\title{
The Translocator Protein (TSPO, 18kDa) as a Potential Molecular Target for Improved Treatment Efficacy in Photodynamic Therapy
}

\author{
Luke Rogers, ${ }^{a}$ Mathias O. Senge $\mathrm{a}^{\mathrm{a}^{*}, \mathrm{~b}}$
}

\author{
* Author for correspondence. \\ a School of Chemistry, SFI Tetrapyrrole Laboratory, Trinity Biomedical Sciences \\ Institute, 152-160 Pearse Street, Trinity College Dublin, Dublin 2, Ireland \\ b Medicinal Chemistry, Institute of Molecular Medicine, Trinity Centre for Health \\ Sciences, Trinity College Dublin, St James's Hospital, Dublin 8, Ireland \\ Tel.: +35318968537 \\ Fax: +35318968536 \\ E-mail: sengem@tcd.ie
}

\begin{abstract}
Since it's serendipitous discovery by researchers over thirty years ago, the translocator protein (18 $\mathrm{kDa})$ (TSPO) has been demonstrated to play an important role in a multitude of critical biological processes. Although implemented as a novel therapeutic and diagnostic tool for a variety of disease states, its most promising role is as a molecular target for anti-cancer treatments such as photodynamic therapy (PDT). This review gives an overview of the attempts made by researchers to design porphyrin based photosensitizers for use as anti-cancer therapeutics in PDT as well as improved imaging agents for diagnostic purposes. With a better understanding of the structure and function of the TSPO, the synthesis of porphyrins for use in PDT with optimum binding affinities will become ever more possible.
\end{abstract}


ReVIEW | Rogers AND SENGE

Contents (for reviewers only)

\section{Abstract}

Defined key terms

TSPO

- Background

- Function

- Structure

- Ligands

Photodynamic Therapy

- PDT: Principle

- Photosensitizer

TSPO as a Porphyrin Target

- Porphyrins as Endogenous Ligands

- Exogenous PDT Drugs

- Porphyrins for PET and PDT

- Modelling and Structural Investigations

- The Situation in Plants

- TSPO and Porphyrias?

Future Perspective

Acknowledgements

Financial and conflict of interest disclosure

References

Executive Summary

Figures, Schemes, Tables, and Boxes 


\section{Defined key terms}

\section{PHOTOSENSITIZER}

A photosensitizer is a molecule that typically sensitizes living cells or tissue to light. The photosensitizer achieves this through promotion to an excited state upon absorption of light. This excited species then may undergo inter-system crossing to produce singlet oxygen.

\section{REACTIVE OXYGEN SPECIES}

Oxygen species such as singlet oxygen, hydrogen peroxide or superoxide anions can be formed by several different biological mechanisms. These molecules can damage cell structures or other molecules within close proximity.

\section{PET}

Positron emission tomography (PET) is a clinical three dimensional imaging method which relies on the incorporation of radiolabelled molecules into tissue. The emitted $\gamma$-rays are detected as a tool for constructing tomographic images by computer analysis.

\section{PHOTOTHERAPY}

The use of light of a specific wavelength to treat a number of biological disorders such as eczema, acne vulgaris and cancer.

\section{PORPHYRIA}

A group of inherited or acquired disorders caused by deficiencies in the enzymes involved in the biosynthetic pathway of heme. These disorders vary in severity and may manifest with skin problems, muscle weakness vomiting, abdominal pain, seizures or neurological issues or occasionally a combination of the above. 


\section{TSPO}

\section{- Background}

The translocator protein $(18 \mathrm{kDa})$ is a five transmembrane domain protein that is localized primarily in the outer mitochondrial membrane [1] and is expressed predominantly in steroid-synthesizing tissues and the brain [2]. The TSPO was identified in 1977 whilst researchers were searching for binding sites for benzodiazepines such as diazepam in peripheral tissue [3]. Thus, the receptor was initially named the peripheral-type benzodiazepine receptor. This aimed at distinguishing these 'peripheral type' benzodiazepine receptors from the central benzodiazepine receptor, which is part of the $G_{A B A}$ receptor complex, typically found in the brain [4]. A number of contentious issues arose with the term 'peripheral-type benzodiazepine receptor' as numerous ligands other than benzodiazepines bind to it. Additionally, this name did not give an accurate representation of the tissue distribution of the molecule as well as the fact that the protein is not in strict terms a receptor itself. To resolve these issues Papadopoulas et al. suggested the term translocator protein (18 kDa) (TSPO), as it has since been discovered to be a subunit of the mitochondrial permeability transition pore (MPTP). This pore consists of the TSPO, voltage-dependent anion channel (VDAC) and the mitochondrial inner membrane adenine nucleotide translocator (ANT) (Figure 1) $[5,6]$.

\section{$<$ Figure 1>}

While an important regulatory complex in its own right, the evidence is mounting that the TSPO could be used as a target of choice in cancer therapy. A major cause of treatment failure in human cancers is the evasion of cell death $[7,8]$. Thus, drugs designed to activate the cell death machinery may represent a more effective therapeutic option. A potent way of unleashing the machinery composed of activators such as catabolic hydrolases, proteases and nucleases is through the permeabilization of the mitochondrial outer membrane. Multiple apoptosis-inducing and necrosis-inducing biochemical cascades converge on mitochondria to cause their deregulation and permeabilization [9]. Mitochondrial dysfunctions have been linked to multiple hallmarks of cancer including insensitivity to anti-growth signals, limitless proliferative potential, impaired apoptosis, enhanced anabolism and decreased autophagy, making mitochondrially-targeted compounds a promising approach to eradicate chemotherapy-refractory cancer cells $[10,11]$. The antiapoptotic effect of Bcl-2 proteins and myeloid cell leukemia sequence 1 (MCl1) were shown to be blocked by the TSPO [12,13], which suggests that Bcl-2 imposed chemoresistance may be avoided by exploiting the TSPO $[13,14]$.

\section{- Function}

As a major component of the outer mitochondrial membrane, TSPO mediates various mitochondrial functions, including cholesterol transport and steroid hormone synthesis, mitochondrial respiration, mitochondrial permeability transition (MPT) pore opening, apoptosis and cell proliferation [15]. It is involved in numerous other functions including, heme biosynthesis, porphyrin transport and calcium channel modulation [16]. In addition, TSPO plays an important role in the regulation of stress response, anxiety disorders and neurodegenerative disorders (Parkinson's disease and Alzheimer's disease) [2]. Elevated TSPO expression is also related to certain cancers, such as those of the breast, colon-rectum, and prostate tissue, and has 
been proposed as a novel prognostic indicator of an aggressive phenotype for these indications [17]. The same situation was revealed for glial cells, where different types of cancers show different TSPO expression, characteristic for specific lines [18].

As a result, the possible use of the TSPO as a target for chemotherapy and as a marker of neoplastic growth has begun to attract considerable attention due to its up-regulation within tumors. The unrestricted growth of tumorgenic tissues is partially due to the altered up-regulation of cellular processes, such as those connected with cholesterol transport and the mitochondria [19].

TSPO ligands induce cell-cycle arrest and, for example, the apoptosis of human colorectal carcinoma cell lines in vitro compared with in normal human colon tissues $[20,21]$. In addition, a correlation between the progression of prostate, breast and colorectal cancer and the overexpression of TSPO has been shown $[22,23,24,25,26]$. There may, however, be other contributing factors such as the tissue of origin that may be instrumental in determining the role of the TSPO in cell proliferation [27]. Researchers were able to demonstrate that deregulation of TSPO expression or function contributes to cellular changes such as apoptosis during tumor progression [28]. These observations indicate that the TSPO could be an interesting target for the development of future anti-cancer therapeutics.

As mentioned previously, the TSPO plays a crucial role in a number of biological functions such as normal cellular homeostasis (Figure 2). This pivotal role is demonstrated by a TSPO -/- mutant, which results in an embryonic lethal phenotype in mice [29]. As a member of the mitochondrial permeability transition pore it is responsible for binding and transporting cholesterol into the mitochondria, where it is converted to pregnenolone. The translocator is also involved in the transport of preproteins into mitochondria. These preproteins are synthesized on cytosolic polysomes and are located within mitochondrial subcompartments. Significant mitochondrial resources and bioenergetics activity are required for cellular proliferation and thus the import of these proteins for mitochondrial biogenesis and metabolism is an important factor in the cell cycle.

$<$ Figure 2>

The MPTP maintains transmembrane potential through active pore opening and closing during normal homeostatic conditions. Apoptotic factors, such as cytochrome $c$ or apoptosis-inducing factor (AIF) may be released from the mitochondria into the cytosol during periods of prolonged opening of the MPTP $[16,30]$. Cell death may arise from this subsequent release as these apoptotic factors can induce osmotic swelling of the mitochondrial matrix which initiates a necrotic signaling cascade, ultimately ending in cell death [31].

\section{- Structure}

Thus far, detailed X-ray crystallographic structural investigations of the TSPO have been hampered by difficulties expressing, purifying and stabilizing this membranebound protein. Other approaches, such as nuclear magnetic resonance and thermodynamic simulations have been employed and resulted in its description as a $18 \mathrm{kDa}$ protein with five transmembrane spanning domains [32]. Recently, singleparticle helical reconstruction and electron cryo-microscopy were used to obtain a three dimensional structure of the Rhodobacter sphaeroides TSPO at $1 \mathrm{~nm}$ resolution [33]. This study details that two TSPO monomers form a tightly associated symmetric dimer in the membrane place, each with five transmembrane $\alpha$-helices, although the exact functional role of the dimerization is not clear yet. 


\section{- Ligands}

The two classes of ligands which have been pivotal to the elucidation of the structure and function of the TSPO have been the benzodiazepines and isoquinoline carboxamides (Figure 3). Both classes of compounds are selective for the TSPO and display nanomolar affinities [34]. [ $\left.{ }^{11} \mathrm{C}\right] \mathrm{PK}-111954$ was the first radiolabelled example of an isoquinoline carboxamide ligand for the TSPO. Although the benzodiazepine $\left[{ }^{11} \mathrm{C}\right]$ Ro $5-48645$ is a competitive binder for TSPO derived from rat kidney, it fails to maintain its affinity across species. Cloning studies have shown a high affinity of $\mathbf{5}$ for rodent-derived TSPO $\left(K_{D}=1-9 \mathrm{nM}\right)$ but a markedly reduced affinity for human TSPO $\left(K_{D}=54 \mathrm{nM}\right)[35]$.

However research has shown that TSPO ligands have no general structure, and porphyrins such as protoporphyrin IX (PP IX, the biosynthetic precursor of heme) $\mathbf{1 1}$ have shown to be the only endogenous ligands that bind with nanomolar affinity to TSPO [36]. This high affinity is selective for the TSPO by a factor of 1000 compared to the affinity for central benzodiazepine receptors. In this context it was postulated that the TSPO facilitates the transport of porphyrins into the mitochondria, as the first and final stages of heme biosynthesis take place in the mitochondria. This hypothesis would then explain the strong affinity of protoporphyrin for the receptor and would create a possible link between a deficiency in this receptor and development of porphyrias (vide infra).

Despite being extensively studied for over 30 years, the TSPO's role in pathophysiology has still not completely been elucidated. Partly this is the result of the absence of high resolution structures and of difficulties in interpreting imaging and pharmacological data [37]. Growing evidence from recent studies has confirmed that multiple binding sites exist and it is now logical to assume that not all newly discovered ligands for the TSPO will only be competitive binders for the isoquinoline site $[38,39]$.

As a consequence of the marked up-regulation of TSPO in active disease states it has proven an attractive target for in vivo imaging of disease progression using functional imaging modalities such as positron emission tomography (PET) [34,40]. Although radiolabelled derivatives of PK11195 4 [41] and Ro 5-4864 5 [42] have been the gold standard of imaging agents for the TSPO (Figure 3), these molecules still suffer from some limitations, such as the poor pharmacokinetic profile of the isoquinolines and poor performance of the benzodiazepines as imaging agents. Thus, a need exists to develop improved TSPO labeling agents for the in vivo study of the TSPO [42].

As progression of diseases and diminished survival rates can archetypally be linked with TSPO expression it has been an obvious target for imaging studies. Notably, Manning's group has explored the use of TSPO ligands as imaging agents for colon [43] and breast cancer [44], and glioma [45,46] with agents which potentially could be used as cancer imaging biomarkers. They focused on the pyrazolopyrimidine scaffold, specifically modified at the 5-, 6-, and 7-positions in an attempt to synthesize higher affinity ligands for the TSPO, which in turn may serve as more robust PET agents in vivo. They identified 2-(5,7-diethyl-2-(4-(2fluoroethoxy)phenyl)pyrazolo[1,5-a]-pyrimidin-3-yl)-N,N-diethylacetamide 7 to be a selective ligand for the TSPO (Figure 4). It exhibited an excellent 36-fold enhancement in affinity compared to the known pyrazolopyrimidine (DPA-714) [47]. Next they synthesized a ${ }^{18} \mathrm{~F}$ radiolabeled analogue of 7 , which displayed negligible accumulation in normal brain tissue, but gave first-rate imaging contrast due to 
strong accumulation in tumor tissue in in vivo studies of healthy rats and a preclinical model of glioma. Clearly, there is therapeutic potential for $\mathbf{8}$ as a novel PET ligand for assessing TSPO expression in tumors [48].

$<$ Figure 4>

\section{Photodynamic Therapy}

\section{- PDT: Principle}

Photodynamic therapy (PDT) is a selective treatment, which can be used as an alternative or in addition to classical therapies, e.g., chemotherapy [31,49]. PDT involves the administration of a tumor localizing photosensitizing agent followed by activation of the agent by light of a specific wavelength (Figure 5). This approach generates a sequence of photochemical and photobiological processes that cause irreversible photodamage to tumor tissue. PDT as a treatment holds many advantages over traditional cancer treatments such as radiation therapy, chemotherapy and surgery as PDT is a relatively non-invasive treatment which has the potential to selectively destroy tumor cells whilst sparing healthy tissue. It can be applied to places deemed non-viable by surgery and it is more controllable and less destructive on the body meaning older patients and others vulnerable to other treatment modalities can be treated with PDT.

\section{$<$ Figure 5>}

Selectivity is achieved partly by the photosensitizer (PS), such as the compounds described below, which have a natural proclivity to accumulate in malignant cells/tissue [50], and by localized application of the incident light to the desired area. Interest currently lies in the advancement of efficient and specific carrier delivery platforms for systemic PDT, be it as bioconjugates [51], by encapsulating them in liposomes [52] or even connecting them to nanoparticles $[53,54]$ These modifications focus on designing systems to impart greater selectivity and specificity on the photosensitizer in order to enhance cellular uptake.

An alternative method to improve the efficacy and selectivity of these PS's may come through the selection of 'new' molecular targets, e.g., the TSPO. Verma et al. observed that TSPO density in tumors parallels their susceptibility to porphyrincatalyzed phototoxicity [55]. Such data suggests that mitochondrial damage is the proximal event that leads to observed cell death. Porphyrins used in photodynamic therapy may thus enter cells and accumulate on mitochondrial porphyrin transport sites $[56,57,58,59,60]$. Since the lifetime of the porphyrin triplet state is extremely short and their diffusion in space is limited, the photo-induced reactions primarily affect the cell organelles labelled by the PS.

\section{- PDT: Photosensitizers}

The principal characteristic of any photodynamic therapy sensitizer is its capacity to preferentially accumulate in malignant tissue and via the production of cytotoxic species, induce a desired biological effect [61]. By now a wide range of dyes has been screened for their efficacy in PDT. For a molecule to be considered a viable candidate as a photosensitizer it must meet a number of requirements. Generally, they should exhibit a strong absorption in the near infrared region of the electromagnetic spectrum $(600-850 \mathrm{~nm})$, which allows for a deeper penetration of light and show no dark toxicity. Typically they are pure compounds with a stable 
shelf life, constant composition and produce a high quantum yield of singlet oxygen production.

The high quantum yield of singlet oxygen is seen as the most important characteristic when evaluating a dye for its PDT efficacy, as it is this reactive oxygen species which is a key mediator of cell death. A number of different chromophores can generate sufficient quantities of this reactive oxygen species and thus be considered potential photosensitizers for PDT. Examples are methylene blue, porphyrins and hypericin [62,63]. Of these different molecules, a number have seen clinical success as photosensitizers. These range from simple molecules such as $\delta$ aminolaevulinic acid (ALA) [64] to tetrapyrrole formulations such as Foscan ${ }^{\circledR} 9$ [65] or Photofrin ${ }^{\circledR} 10$ (Figure 6) [66].

$<$ Figure 6>

As porphyrins meet most of the traits desired for a photosensitizer and due to the relative commercial success of some of the aforementioned compounds, they have become the most extensively studied class of photosensitizers. Current research is centered on developing successful $3^{\text {rd }}$ generation sensitizers to overcome some of the drawbacks present with Foscan $^{\circledR}$ and Photofrin ${ }^{\circledR}$ and in particular, post-treatment photosensitivity and tissue selectivity $[65,66]$.

As it stands, many, but not all of the "better" photosensitizers for photodynamic therapy are tetrapyrroles which tend to localize in the mitochondria. The induction of apoptosis resulting from the opening of the MPTP by ligands implicates the TSPO in the regulation of apoptotic and necrotic cell death [16]. Ligands of the TSPO also inhibit cell proliferation in cancer cell lines, resulting in an accumulation of cells in the $G_{1} / G_{0}$ phase of the cell cycle. These actions ultimately inhibit the progression of cells to the $S$ and $G_{2 / M}$ phase, in which cell proliferation occurs [67]. By targeting the TSPO with endogenous or exogenous porphyrins, one may be able to selectively induce cell death via pro-apoptotic and anti-proliferative pathways.

\section{TSPO as a Porphyrin Target}

\section{- Porphyrins as Endogenous Ligands}

But the focus on porphyrins in connection with the TSPO story begins with Snyder and coworkers discovering in 1987 that porphyrins are endogenous, potent competitive inhibitors of the TSPO $[36,68,69]$. They found that pure hemin and PP IX 11 competitively inhibit TSPO binding of $\left.{ }^{3} \mathrm{H}\right] \mathrm{PK}-11195$ and $\left.{ }^{3} \mathrm{H}\right] \mathrm{Ro}$ 5-4864 with $K_{\mathrm{i}}$ values of 41 and $15 \mathrm{nM}$, respectively. While their binding activity at central-type benzodiazepine receptors saw a 1000 -fold lower affinity. Tetra- and octacarboxylic acid porphyrins were to a small degree able to displace isoquinoline and benzodiazepine derivatives from binding to the TSPO and inactive in comparison to their dicarboxylic acid porphyrin counterparts, which displayed nanomolar potencies. This finding of porphyrins as endogenous TSPO ligands opened a new field of studies into porphyrins as therapeutic or diagnostic agents pertaining to TSPO related diseases.

Clearly, if porphyrins can bind to TSPO, this must effect the action of porphyrin-based photosensitizers in PDT. One of the most insightful strategies in PDT involves the administration of $\delta$-aminolaevulinic acid (ALA), a biosynthetic precursor of heme, with the aim to boost protoporphyrin IX production in the target cells [70]. Indeed, Furre et al. showed that PP IX produced endogenously by 
hexaaminolaeuvulinate (HAL) localized primarily in the mitochondria of the human cell line Reh [71]. Upon PDT treatment, post irradiation analysis showed that $>80 \%$ of cells died by apoptosis, as indicated electron microscopy. HAL-PDT turned out to be both light dose and time course dependent.

In the biosynthetic pathway of heme, coproporphyrinogen III traverses the channel from the matrix to the cytosol [72]. It is theorized by Furre et al. [71] that HAL-induced endogenous PP IX may also advantageously use this channel for its own transportation into the cytosol. However, the study also showed that exogenous PP IX localizes differently intracellularly than endogenous PP IX and may not target the TSPO sufficiently to produce the same degree of apoptosis. Analysis of competitive binding studies with ligands for ANT suggests that, as a result of its close spatial proximity to the TSPO, the mitochondrial inner membrane adenine nucleotide translocator may be an additional target for HAL-PDT [73]. Their propinquity to HAL-induced endogenous PP IX synthesis at the mitochondrial inner membrane and the possibility that the porphyrin may use ANT for its transportation validates the TSPO as a possible therapeutic target for HAL-based PDT treatment of cancer.

With the exception of ALA and Photofrin ${ }^{\circledR}$ most PS in clinical use or development have chemical substituent pattern quite distinct from PP IX and this raises the question of porphyrin ligand specifity when targeting the TSPO. Kessel et al. conducted a study into the comparative binding of protoporphyrin IX 11 and two structural analogs, PP III 12 and PP XIII 13, using murine leukemia L1210 cell cultures (Figure 7) [74]. The amphiphilicity of porphyrin based PS plays a significant role in the localization and membrane passage [75]. As such, it is important to consider the distribution of polar and hydrophobic substituents around the macrocycle as well as the charge of the side chains present on the molecule $[63,76]$. Kessel et al. suggest that porphyrin accumulation and affinity of the TSPO must be governed by hydrophobic considerations and that a major determinant of PDT efficacy within the PP IX series may be the relative hydrophobicity of the different analogues. All three porphyrins displayed equal hydrophobicity and all three agents induced $30 \%$ to $40 \%$ cell death via apoptosis after light exposure, although only PP IX had a strong affinity for the TSPO. These results suggest that only sensitizers with a configuration similar to protoporphyrin IX may display PDT efficacy as a result of TSPO affinity.

\section{$<$ Figure 7>}

The next question is to what extent can the binding of porphyrins to the TSPO be affected by other factors? Next to hypoxia one other important factor is the intracellular $\mathrm{pH}$. Healthy cells grow in $\mathrm{pH} 7.4$ while cancerous ones, depending on their kind and age, can live in $\mathrm{pH}$ 5.5-6.5 [77]. Bombalska and Graczyk observed a decline in binding constants of a series of protoporphyrin and haematoporphyrin derivatives with increasing acidity of the environment [78]. With decreasing $\mathrm{pH}$ value porphyrin-type photosensitizers occur in different ionic forms and it is possible that the receptor changes its structural conformation in varying environment conditions. $\mathrm{PP}$ IX demonstrated the greatest binding affinity across the $\mathrm{pH}$ range, followed by haematoporphyrin $(\mathrm{Hp}), \mathrm{Hp}(\mathrm{Arg})_{2}$ and $\mathrm{PP}(\mathrm{Arg})_{2}$ [78]. There is also the possibility that a lower $\mathrm{pH}$ value results in porphyrin core protonation [79] with attendant conformational distortion [80] which could impair binding with the receptor $[81,82]$.

This work was followed by studies on the interaction of diamino acid derivatives of protoporphyrin IX, where the vinyl groups have been substituted with amino acids 36-49. The amino acids were installed to facilitate the entry of the 
photosensitizer into the cell by binding to amino acid receptors present in the tumor cell membrane. Preliminary studies indicate selectivity of accumulation of the dyes and low cytotoxicity to normal cells [83]. The strongest binding was observed at $\mathrm{pH}$ 5.5 for all four amino acid derivatives, which was supported by an observed increase in association constants as compared to $\mathrm{pH}$ 7.4. With these results, one can hypothesize that with the progression of cancer, the strength of the binding efficacy will increase as the $\mathrm{pH}$ decreases and therefore an increase in photosensitizer concentration is not necessary so as to achieve the required photodynamic effect.

\section{- Exogenous PDT Drugs}

If endogenous porphyrins bind to TSPO or their level and interaction can be modulated through additional protoporphyrin IX availability what effects can be observed upon the exogenous administration of porphyrin-type PDT drugs? Several studies have addressed questions such as this. For example, Pandey's group used a synthetic library of long-wavelength photosensitizers derived from bacteriopurpurinimide and bacteriochlorin $p_{6}$ for comparative in vitro and in vivo PDT studies in RIF tumors [84]. The capacity of the rhodochlorins 14-18 (Figure 6) to displace the labeled high-affinity TSPO ligand PK11195 4 was measured and it was found that photosensitizers $\mathbf{1 5}, 16$ and $\mathbf{1 7}$ displaced more than $70 \%$ of ${ }^{3} \mathrm{H}-\mathrm{PK} 11195$ at $10^{-4} \mathrm{M}$, whilst 18 displaced about $51 \%$ of ${ }^{3} \mathrm{H}-\mathrm{PK} 11195$. However, no direct correlation between TSPO binding and PDT efficacy was found even though some molecules showed encouraging results in respect to PDT use.

Next, they synthesized a phytochlorin derived from chlorophyll $a$ and evaluated its PDT and tumor imaging capacity in vitro and in vivo [85]. They found methyl 3-(1'-m-iodobenzyloxyethyl)-3-devinylpyropheophorbide a (HPPH) 19 to be a prospective photosensitizer and imaging agent for photodynamic therapy (Figure 8). Five $\mathrm{C} 3 \mathrm{H}$ mice bearing RIF tumors were treated with the non-radiolabelled photosensitizer analogue of $20(21)$ at a drug dose of $1.5 \mu \mathrm{mol} . \mathrm{kg}^{-1}$ and a light dose of $128 \mathrm{J.cm}^{-2}, 14 \mathrm{~mW} . \mathrm{cm}^{-2}$ for $2.5 \mathrm{~h}\left(\lambda_{\max }=665 \mathrm{~nm}\right)$ at $24 \mathrm{~h}$ post injection. A $100 \%$ cure of tumors was achieved, i.e. all mice were tumor free within 60 days. The photosensitizer exhibited promising tumor fluorescence and PET imaging abilities and clearly supports the Pandey's concept of this ${ }^{124}$ I-labeled photosensitizer finding use as a "multimodality agent". In the future, the design and efficacy may be improved upon by incorporating more tumor-avid and/or target specific photosensitizers.

\section{$<$ Figure 8>}

Another example involved the use of bacteriochlorophyll a derivatives. These relatively unstable bacteriochlorins from Rhodobacter shaeroides were converted in situ into a series of stable $N$-hexylimide analogues 22-24 and tested in vitro and in vivo for their efficacy as PDT agents (Figure 9) [86]. The bacteriopurpurinimide 22 gave limited in vivo PDT efficacy in $\mathrm{C} 3 \mathrm{H}$ mice bearing RIF tumors (drug dose 0.2 umol.kg ${ }^{-1}, \lambda_{\max }=780 \mathrm{~nm}, 135 \mathrm{J.cm}{ }^{-2}$ at $24 \mathrm{~h}$ post injection). Two of the more efficacious analogues were $\mathbf{2 3}$ and $\mathbf{2 4}$ however, despite their improved efficacy, displacement studies suggest that they do not have a significant affinity for the TSPO. Comparative intracellular localization studies with Rhodamine 123 found the less effective photosensitizer to be localized in the lysosomes, whereas the most effective one was localized in the mitochondria indicating the possibility for future improvements.

$$
<\text { Figure 9> }
$$


Competitive binding studies of a ${ }^{14} \mathrm{C}$ phthalocyanine photosensitizer against ${ }^{3} \mathrm{H}-\mathrm{PK} 11195$ (4), for binding to rat kidney mitochondria or intact Chinese hamster ovary cells were conducted by Morris et al. [87]. Their results suggest the presence of various binding sites for Pc4 (25) in mitochondria and cells, other than those attributed to PK11195 binding. Chemically this makes sense as phthalocyanines have chemical properties distinct from those of protoporphyrins. Although a low affinity binding site for $\mathbf{2 5}$ was identified, it appears that other mitochondrial events, such as photodamage to Bcl-2 are more pertinent to the phototoxicity of Pc4 (25) PDT than the binding of the phthalocyanine to the TSPO. This suggests that the observed inhibition of Pc4 (25) PDT induced apoptosis by PK11195 likely occurs through a mechanism separate to the TSPO.

\section{- Porphyrins for PET and PDT}

${ }^{11} \mathrm{C}$ and ${ }^{18} \mathrm{~F}$ are the most common PET isotopes used to label drugs $[88,89]$. Unfortunately, both suffer from relatively short half-lifes which limits their use in experiments involving monoclonal antibodies or photosensitizers which take a long time (hours compared to minutes) for accumulation in a tumor. Due to a half-life of 4.2 days, ${ }^{124} \mathrm{I}$ is a more appropriate candidate and this longer half-life makes it compatible for sequential biological imaging using microPET [90,91.92].

With these facts in mind Pandey and coworkers aimed to develop a TSPO targeting photosensitizer for both imaging (PET) and PDT. As mentioned previously, numerous reports in the literature have shown overexpression of TSPO for both colon and breast cancers [22,24]; hence Balb/c mice bearing Colon-26 (colon adenocarcinoma) and EMT6 (well characterized, undifferentiated mouse breast cancer) tumors were selected. The synthesis of ${ }^{124}$ l labeled $\mathbf{2 6}$ was achieved with high (>95\%) radioactive specificity [93].

Use of the radiolabelled derivative of PK11195 $\left({ }^{124} \mathrm{I}-\mathrm{PK} 11195,26\right)$ resulted in a significant improvement of the PDT efficacy of the well-known photosensitizer HPPH (19), once conjugated. Compounds 27 and 28 possess similar binding affinity to the TSPO, however, $\mathbf{2 8}$ exhibited stronger tumor affinity as it possessed a higher standardized uptake value $(\% \mathrm{ID} / \mathrm{g})$ at every time point (Figure 10$)$. Both compounds 27 and 28 are good imaging agents and, interestingly, compound 28 produced significantly less skin phototoxicity than HPPH (19) in Scid mice bearing MDA-231 tumors; one of the main drawbacks of contemporary clinical PDT. Optimal tumor imaging for these compounds were obtained at 48,72 and $96 \mathrm{~h}$ post injection, which further rationalizes the necessity to use ${ }^{124} \mathrm{I}$ instead of the shorter lived ${ }^{18} \mathrm{~F}$ (Figure 11 95). These results clearly indicate that a conjugation of PK11195 to photosensitizers increases the PDT efficacy and target specificity compared to the photosensitizer alone.

$<$ Figure 10>

$<$ Figure 11>

Related studies used pyropheophorbides and their respective metal complexes to ascertain their viability as nonradioactive TSPO binding probes [94]. The TSPO binding and photosensitizing efficacy was influenced substantially by the presence of a core metal and as these compounds display strong fluorescence, they have significant potential to replace radioactive TSPO probes. For example, porphyrin 29, an indium(III) complex proved to be the most efficacious with respect to photosensitizing efficacy. In vitro experiments with mice bearing RIF tumors (light

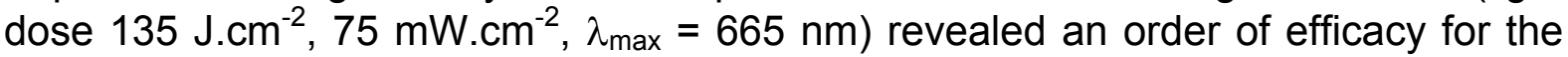
central metal of $\ln (\mathrm{III})>2 \mathrm{H}>\mathrm{Zn}(\mathrm{II})>\mathrm{Ni}(\mathrm{II})$. This might be related to their singlet 
oxygen production capabilities. Although the Nickel complex $\mathbf{3 0}$ produced no PDT effect as expected, it did have the strongest binding affinity to TSPO, comparable to that of PK11195. Again in vitro efficacy and TSPO binding efficacy showed no direct correlation and no relationship was seen between TSPO binding and in vitro PDT efficacy.

As synthetic bacteriochlorins are good prospective PDT agents [63,95] some of them were also investigated in the context of the TSPO [96]. Benzobacteriochlorins derived from vic-dihydroxybacteriochlorins have long wavelength absorption in the range of 737 to $805 \mathrm{~nm}$ and were used in in vitro (RIF tumor cells) and in vivo ( $\mathrm{C} 3 \mathrm{H} / \mathrm{HeJ}$ mice bearing RIF tumors) tests (Figure 12). The benzobacteriochlorin $\mathbf{3 1}$ was found to be the most efficacious and displayed reduced skin phototoxicity compared to Photofrin $^{\circledR}$ at their respective therapeutic doses. Displacement studies were undertaken against ${ }^{3} \mathrm{H}-\mathrm{PK} 11195$ (4) and indicated that increasing concentrations of mitochondrial located benzobacteriochlorins 31-35 did not result in a higher displacement of ${ }^{3} \mathrm{H}-\mathrm{PK} 11195$. This suggests that, for these benzobacteriochlorins, the TSPO is not the target site.

\section{$<$ Figure 12>}

Likewise, octaethylporphyrin-derived benzochlorins with varying degrees of lipophilicity were evaluated in an in vitro and in vivo SAR study [97]. A number of different structural features, such as the length of alkyl or fluoroalkyl groups attached to the exocyclic ring either by a carbon-carbon or ether linkage, were assessed. All of the (benzochlorinato)zinc(II) compounds were found to be effective with analogues 40, 41 and 42 giving the best in vivo $(\mathrm{C} 3 \mathrm{H} / \mathrm{HeJ}$ mice) results, with three out of six mice tumor free after 90 days $\left(1.0 \mu \mathrm{mol} . \mathrm{kg}^{-1}\right.$ dose $)$. Of the two compounds 40 and $\mathbf{4 3}$ the $\mathrm{Zn}(\mathrm{II})$ complex produced $100 \%$ cell kill (RIF tumor cells) at 4.0 and 6.0 $\mathrm{J} . \mathrm{cm}^{-2}$. Comparative intracellular localization and binding studies with Rhodamine123 and ${ }^{3} \mathrm{H}-\mathrm{PK} 11195$ (4) indicate that the PSs localize in the mitochondria. However, no specific displacement of ${ }^{3} \mathrm{H}-\mathrm{PK} 11195$ (4) was observed, i.e. no direct correlation exists between binding affinities and photosensitizing efficacy.

\section{- Modelling and Structural Investigations}

Recent studies on the role of the interaction of PP IX and the TSPO in porphyrinbased photodynamic therapy focused on structural and modelling studies. By using Escherichia coli Papadopoulos et al. were able to express recombinant mouse TSPO in order to investigate the validity of their hypothesis that the interaction of PP IX with the TSPO is involved in the regulation of heme biosynthesis [98]. The E. coli protoplasts produced a recombinant gene product that showed specific affinity for PP IX binding.

The interaction of PP IX and TSPO in various cell models [99,100,101] has been suggested to assist the modus operandi of porphyrin based photosensitization in photodynamic therapy (PDT) of tumors [102]. These experiments found that neither PK 11195 nor Ro5-4864 could increase the PP IX binding or uptake, which was in accordance with previous studies [103]. Protoporphyrin IX could displace a radiolabeled analogue of PK 11195 from the TSPO but not that of Ro 5-4864, which indicated the presence of separate but overlapping binding sites [103,104]. Interpretation of these results suggest that the TSPO protein is solely responsible for PP IX binding and transport [74,98].

Bacterial TspO have been used to develop a functional model of the receptor. A number of TSPO mutants were synthesized by Yeliseev and Kaplan to investigate 
the significance of a number of amino acid residues on the functional activities of TspO [105]. Many of the amino acid residues involved in TSP function are highly conserved among $R$. capsulatus CrtK, $R$. sphaeroides TspO and their mammalian analogues. The first putative periplasmic loop of TSPO, located between the first and second membrane spanning domain, contains a clustering of highly conserved amino acid residues. These residues are $\operatorname{Leu}^{34}, \mathrm{Lys}^{36}, \operatorname{Trp}^{30}, \operatorname{Trp}^{39}, \operatorname{Trp}^{44}, \operatorname{Trp}^{50}$, $\operatorname{Trp}^{135}, \mathrm{Gln}^{80}$, and $\operatorname{Arg}^{96}$ [106]. This might suggest the direct interaction of the first putative loop with a specific ligand or cofactor, e.g., a tetrapyrrole. This loop contains a number of tryptophan residues, which could support its involvement in tetrapyrrole ligand binding. This is based on the heme binding motif (WWD), which is found in proteins involved in transmembrane heme delivery [107].

This proposed model, where the N-terminus of TSPO is exposed to the cell exterior may contradict the theorized structural model for the mammalian TSPO, which proposes that the $\mathrm{N}$-terminal region of the protein is located on the matrix side of the outer mitochondrial membrane and that the first putative loop is exposed to the cytoplasm [38,108]. However, it appears permissible to anticipate that the tetrapyrrole binding site on the TSPO be exposed to the periplasmic space due to its part in the biosynthetic pathway for heme. The synthesis of TSPO in the cytoplasm and subsequent importation into the mitochondrial matrix before re-entering the mitochondrial outer membrane supports this new inside-out topology relative to bacterial topology [108]. Previous studies indicated the significance of Lys ${ }^{39}$ (corresponding to Lys ${ }^{36}$ of the TspO sequence) in binding of Ro5-4864, and of Trp ${ }^{42}$ and $\operatorname{Trp}^{47}$ (corresponding to $\operatorname{Trp}^{39}$ and $\operatorname{Trp}^{44}$ of the TspO sequence) in binding of PK11195 and Ro5-4864 [38]. This supports the participation of the conserved amino acids discussed above in binding TSPO ligands in the mammalian TSPO [38]. Parallels between the structural and functional properties of the bacterial TspO and the mammalian homologue are mounting and this study provides further support for the theory [109].

Some information on the binding sites for endogenous ligands of the TSPO dimer model, could be derived from competitive binding studies using PK11195, PP IX and cholesterol. Some level of interaction among all three binding sites of the TSPO appears to be present [110]. These results are representative of a model in which PK11195 and PP IX interacting at somewhat different positions on extramembrane loop 1 (Figure 13). The model suggests that the porphyrin may initially bind at loop 1, en route to transport via the dimer interface, as demonstrated in Figure 12. This proposed binding model matches previous in vivo studies in RsTspO [106], which also suggested that loop 1 plays a critical role in the binding and export of porphyrins [111,105,112]. Despite these correlations, it is unlikely that the first putative loop 1 is the only contributor to the binding of PP IX. Using a tryptophan fluorescence quenching assay for TSPO investigations it was observed that the tryptophan fluorescence was quenched evenly and completely by PP IX while no such effect was found with PK11195 and other ligands. Thus, PP IX may interact with a rather large area its binding induces a global conformational change [33].

$<$ Figure 13>

One suggestion is that protoporphyrin IX may bind to a large area or induce a global conformational change, both of which are conceivable if PP IX is being bound and transported through the dimer interface [110]. This was based on the observed quenching of the tryptophan fluorescence by PP IX but not by PK11195 and other ligands. Decreased porphyrin export activity in phenylalanine mutants of W44 and W50 (single amino acid substitution with elevated levels of accessory pigments), 
indicates changes in TSPO function [106]. This indicates that aromatic residues on transmembrane helix II play an important role in porphyrin binding and transport. A W38C mutant showed a $\sim 6$-fold reduction in affinity of PP IX for R.s. TSPO which is the location in loop 1 that initial binding occurs [98]. Although PK11195 was reported to compete with PP IX binding and bind to loop 1 of the TSPO, results from tryptophan quenching experiments indicate that they do not bind in precisely the same location.

All modelling studies suggest that the last two-thirds of loop 1 are highly conserved across all species. The observation that the $K_{d}$ values of both PK11195 and PP IX were distinctly lower in the W38C mutant suggests some overlap between PK11195 and PP IX [110]. These independent lines of evidence allowed Miller et al. [110] to propose that within the monomer, PK11195 interacts mainly on the first half of loop 1, extending to residue W38 (S41 in human).

\section{- The Situation in Plants}

Although unrelated to clinical applications it may be illustrative to take a quick look at the situation in plants. After the initial impetus from studies in mammals the search began for analogous mitochondrial import mechanisms in plants [113] and such a system was first identified by Lindemann et al in 2004 [114]. Substantial similarities to the Rhodobacter TspO protein and the mammalian TSPO were found in protein sequences from Arabidopsis thaliana [114,115]. The recombinant gene product of a TSPO-homologues Arabidopsis sequence was cloned and expressed in E. coli and displayed high binding affinity for benzodiazepines [114]. A comparative benzodiazpepine-stimulated uptake of PP IX and cholesterol was observed when the protein was applied to $E$. coli protoplasts. This TSPO-like protein appears from these results to be involved in the directing of protoporphyrinogen IX to the mitochondrial site of protoheme formation and steroid import.

The gene sequencing of Arabidopsis thaliana identified a single TSPO related gene with a 40 amino acid $\mathrm{N}$-terminal extension compared to the bacterial or mammalian species. This discovery suggest that site of localization may be in the mitochondria or chloroplast [113]. It has also been suggested that the At-TSPO plays a part in the response of Arabidopsis to high salt stress as re-localization of the AtTSPO from the ER to chloroplasts through its $\mathrm{N}$-terminal extension occurs under high salt stress.

Further studies on different plant species investigated the central and peripheral-type benzodiazepine receptors in pods and leaves of Ceratonia Siliqua [116]. Using $\left[^{3} \mathrm{H}\right] \mathrm{PK} 11195$ and $\left[{ }^{3} \mathrm{H}\right] \mathrm{RO}$ 15-1788 (8-fluoro-3-carbethoxy-5,6-dihydro5-methyl-6-oxo-4-imidazo-[1,5-a]-1,4-benzodiazepine) as specific ligands in a radioreceptor binding assay, the authors observed the presence of compounds which could readily displace the radiolabelled ligands from their respective binding sites. TSPO acting compounds were found to be extremely concentrated in young leaves suggesting that these compounds may play a significant role in cell growth and proliferation.

\section{- TSPO and Porphyrias?}

The TSPO seems to play a critical role in the production of neurosteroids, which are able to alter the electrical properties of neuronal membranes and thus the firing patterns of neurons. Porphyrias, inherited or acquired disorders of certain enzymes that normally participate in the production of porphyrins and heme, are known to give 
rise to certain aspects of neuropsychiatric disorders, such as schizophrenic-like symptoms [16].

Intriguingly, the binding capacity of TSPO for heme precursors is significantly reduced in schizophrenia patients with predominantly negative symptoms (residual type) compared to schizophrenia patients with predominantly positive symptoms. Additionally, no correlation was observed between TSPO density and age, gender and anti-psychotic medication, nor between variations of the TSPO gene and schizophrenia [117]. However, there was a decrease in TSPO density in postmortem brains of chronic schizophrenia patients [117]. Additionally, Ritsner et al. found a connection between decreased TSPO density in blood platelets of schizophrenic patients exhibiting aggressive behavior [118]. The decrease in TSPO density was around $30 \%$ in patients and the $B_{\max }$ value was inversely correlated with aggressive behavior scores $(r=0.36, p=0.023)$.

Porphyrias typically arise due to an accumulation of heme precursors, i.e. atypical porphyrins, in tissue due to a deficiency in one or more of the enzymes associated with the heme biosynthetic pathway. Medical conditions associated with porphyrias vary depending on which enzyme in the biosynthetic pathway is deficient. Porphyrias associated with coproporphyrinogen III oxidase and protoporphyrinogen oxidase are the most likely to display neurological symptoms [119]. Interestingly, no research has been conducted into the possible correlation between this decreased TSPO density in aggressive schizophrenic patients and the manifestation of a porphyria. As the TSPO is a transporter for heme precursors into the mitochondria, a $30 \%$ decrease in TSPO density may cause an accumulation of porphyrins in the cytosol and therefore potentially a porphyria.

\section{FUTURE PERSPECTIVE}

It has now been demonstrated that there are additional binding sites on the TSPO that are not related to isoquinoline compounds and due to this the current screening methods fall short of addressing all potential binding sites. Furthermore, noted species differences suggest that in vitro results using animal-derived TSPO, as well as in vivo imaging of animals, cannot necessarily be translated to human studies. Also, while establishing the $K_{\mathrm{i}}$ of a compound allows for relative comparison of affinity it does not address the capacity to measure increased binding site density $\left(B_{\max }\right)$.

Despite all the major advances in the understanding of the structure and function of the TSPO, it is still unclear precisely how the TSPO acts in the binding of tetrapyrrole substrates $[120,121,122,76]$. Several groups have trialed numerous synthetic analogues of the endogenous ligand PP IX but still have no definitive understanding or predictive model of whether a compound will bind to the TSPO. Due to the flexible nature of loop 1, further modeling studies need to be conducted and ligand-protein interactions need to be deciphered to give a more rational approach to their drug design. Ultimately, this will require a high-resolution structure with bound ligand.

Although PDT efficacy and TSPO binding can still not conclusively be correlated the TSPO still represents an intriguing target for PDT research. One possibility may be the use of a larger library of carboxylic acid based porphyrins with varying degrees of hydrophobicity in order to obtain a better understanding of the structural tolerance, if any, of the TSPO for macrocycle variation. 


\section{Acknowledgments}

Our work was supported by grants from Science Foundation Ireland (SFI P.I. 09/IN.1/B2650 and 12/TIDA/B2381).

\section{Financial and competing interest disclosure}

The authors have no financial interest or conflict of interest related to the subject matter of this review.

\section{References}

1 Scarf AM, Kassiou M. The Translocator Protein. J. Nucl. Med. 52, 677-680 (2011).

2 Rupprecht R, Papadopoulos V, Rammes G, Baghai TC, Fan J, Akula N, Groyer G, Adams D, Schumacher M. Translocator protein (18 kDa) (TSPO) as a therapeutic target for neurological and psychiatric disorders. Nat. Rev. Drug Discov. 9, 971-988 (2010).

3 Braestrup C, Squires RF. Specific benzodiazepine receptors in rat brain characterized by high-affinity $(3 \mathrm{H})$ diazepam binding. Proc. Natl. Acad. Sci. USA 74, 3805-3809 (1977).

4 Lambert JJ, Belelli D, Hillvenning C, Peters JA. Neurosteroids and GABA $_{A}$ Receptor Function. Trends Pharmacol. Sci. 16, 295-303 (1995).

5 Papadopoulos V, Baraldi M, Guilarte TR, Knudsen TB, Lacapere JJ, Lindemann P, Norenberg MD, Nutt D, Weizman A, Zhang MR, Gavish M. Translocator protein $(18 \mathrm{kDa})$ : new nomenclature for the peripheral-type benzodiazepine receptor based on its structure and molecular function. Trends Pharmacol. Sci. 27, 402-409 (2006).

6 Fan J, Lindemann P, Feuilloley MG, Papadopoulos V. Structural and Functional Evolution of the Translocator protein (18 kDa). Curr. Mol. Med. 12, 369-386 (2012).

7 Hanahan D, Weinberg RA. The hallmarks of cancer. Cell 100, 57-70 (2000).

8 Fulda S. Tumor resistance to apoptosis. Int. J. Cancer 124, 511-515 (2009).

9 Kroemer G, Galluzzi L, Brenner C. Mitochondrial membrane permeabilization in cell death. Physiol. Rev. 87, 99-163 (2007).

10 Kroemer G, Pouyssegur J. Tumor cell metabolism: cancer's Achilles' heel. Cancer Cell 13, 472-482 (2008).

11 Galluzzi L, Morselli E, Kepp O, Vitale I, Rigoni A, Vacchelli E, Michaud M, Zischka H, Castedo M, Kroemer G. Mitochondrial gateways to cancer. Mol. Aspects Med. 31, 1-20 (2010).

12 Okaro AC. Fennell DA, Corbo M, Davidson BR, Cotter FE. PK11195, a mitochondrial benzodiazepine receptor antagonist, reduces apoptosis threshold in $\mathrm{Bcl}-\mathrm{X}_{\mathrm{L}}$ and $\mathrm{Mcl}-1$ expressing human cholangiocarcinoma cells. Gut $51,556-$ 561 (2002).

13 Decaudin D, Castedo M, Nemati F, Beurdeley-Thomas A, De Pinieux G, Caron A, Pouillart P, Wijdenes J, Rouillard D, Kroemer G, Poupon MF. Peripheral benzodiazepine receptor ligands reverse apoptosis resistance of cancer cells in vitro and in vivo. Cancer Res. 62, 1388-1393 (2002).

14 Fulda S, Galluzzi L, Kroemer G. Targeting mitochondria for cancer therapy. Nat. Rev. Drug Discov. 9, 447-464 (2010). 
15 Shoshan-Barmatz V, Israelson A, Brdiczka D, Sheu SS. The voltage-dependent anion channel (VDAC): function in intracellular signalling, cell life and cell death. Curr. Pharm. Des. 12, 2249-2270 (2006).

16 Veenman L, Papadopoulos V, Gavish M. Channel-like functions of the 18-kDa translocator protein (TSPO): regulation of apoptosis and steroidogenesis as part of the host-defense response. Curr. Pharm. Des. 13, 2385-2405 (2007).

17 Batarseh A, Papadopoulos V. Regulation of translocator protein 18 kDa (TSPO) expression in health and disease states. Mol. Cell Endocrinol. 7, 1-12 (2010).

18 Chen MK, Guilarte TR. Translocator Protein 18kDA (TSPO): Molecular Sensor of Brain Injury \& Repair. Pharmacol. Ther. 118, 1-17 (2008).

19 Liu J, Rone MB, Papadopoulos V. Protein-protein interactions mediate mitochondrial cholesterol transport and steroid biosynthesis. J. Biol. Chem. 15, 38879-38893 (2006).

20 Maaser K, Höpfner M, Jansen A, Weisinger G, Gavish M, Kozikowski AP, Weizman A, Carayon P, Riecken EO, Zeitz M, Scherübl H. Specific ligands of the peripheral benzodiazepine receptor induce apoptosis and cell-cycle arrest in human colorectal cancer cells. Br. J. Cancer 85, 1771-1780 (2001).

21 Kugler W, Veenman L, Shandalov Y, Leschiner S, Spanier I, Lakomek M, Gavish M. Ligands of the mitochondrial $18 \mathrm{kDa}$ translocator protein attenuate apoptosis of human glioblastoma cells exposed to erucylphosphohomocholine. Cell Oncol. 30, 435-450 (2008).

22 Carmel I, Fares FA, Leschiner S, Scherubl H, Weisinger G, Gavish M. Peripheral-type benzodiazepine receptors in the regulation of proliferation of MCF-7 human breast carcinoma cell line. Biochem. Pharmacol. 58, 273-278 (1999).

23 Batra S, Alenfall J. Characterization of peripheral benzodiazepine receptors in rat prostatic adenocarcinoma. Prostate 24, 269-278 (1994).

24 Katz Y, Eitan A, Gavish M. Increase in peripheral benzodiazepine binding sites in colonic adenocarcinoma. Oncology 47, 139-142 (1990).

25 Katz Y, Ben-Baruch G, Kloog Y, Menczer J, Gavish M. Increased density of peripheral benzodiazepine-binding sites in ovarian carcinomas as compared with benign ovarian tumours and normal ovaries. Clin. Sci. 78, 155-158 (1990).

26 Batra S, losif CS. Peripheral benzodiazepine receptor in human endometrium and endometrial carcinoma. Anticancer Res. 20, 463-466 (2000).

27 Sakai M, Ferraz-de-Paula V, Ribeiro A, Quinteiro-Filho WM, Rone MB, Martinez-Arguelles DB, Dagli MLZ, Papadopoulos V, Palermo-Neto J. Translocator protein $(18 \mathrm{kDa})$ mediates the pro-growth effects of diazepam on Ehrlich tumor cells in vivo. Eur. J. Pharmacol. 626, 131-138 (2010).

28 Batarseh A, Barlow KD, Martinez-Arguelles DB, Papadopoulos V. Functional characterization of the Human Translocator Protein (18 kDa) Gene Promoter in Human Breast Cancer Cell Lines. Biochim. Biophys. Acta. 1819, 38-56 (2012).

29 Papadopoulos V, Amri H, Boujrad N, Cascio C, Culty M, Garnier M, Hardwick M, Li H, Vidic B, Brown AS, Reversa JL, Bernassau JM, Drieu K. Peripheral benzodiazepine receptor in cholesterol transport and steroidogenesis. Steroids, 62, 21-28 (1997).

30 Parker MA, Bazan HE, Marcheselli V, Rodriguez de Turco EB, Bazan NG. Platelet activating factor induces permeability transition and cytochrome $C$ release in isolated brain mitochondria. J. Neurosci. Res. 69, 39-50 (2002).

31 De Rosa A, Naviglio D, Di Luccia A. Advances in Photodynamic Therapy of cancer. Curr. Cancer Ther. Rev. 14, 234-247 (2011). 
32 Scarf AM, Ittner LM, Kassiou M. The translocator protein (18 kDa): central nervous system disease and drug design. J. Med. Chem. 52, 581-592 (2009).

33 Korkhov VM, Sachse C, Short JM, Tate CG. Three-dimensional structure of TspO by electron cryomicroscopy of helical crystals. Structure. 18, 677-687 (2010).

34 Luus C, Hanani R, Reynolds A, Kassiou M. The development of PET radioligands for imaging the translocator protein $(18 \mathrm{kDa})$ : What have we learned? J. Label. Compd. Radiopharm. 53, 501-510 (2010).

35 Sprengel R, Werner P, Seeburg PH, Murkin AG, Santi MR, Grayson DR, Guidotti A, Krueger KE. Molecular cloning and expression of c-DNA encoding a peripheral-type benzodiazepine receptor. J. Biol. Chem. 264, 20415-20421 (1989).

36 Verma A, Nye JS, Snyder SH. Porphyrins are endogenous ligands for the mitochondrial (peripheral-type) benzodiazepine receptor. Proc. Natl. Acad. Sci. USA 84, 2256-60 (1987).

37 Pavese N, Gerhard A, Tai YF, Ho AK, Turkheimer F, Barker RA, Brooks DJ, Piccini P. Microglial activation correlates with severity in Huntington disease: a clinical and PET study. Neurology. 66, 1638-1643 (2006).

38 Farges R, Joseph-Liauzun E, Shire D, Caput D, Le Fur G, Ferrara P. Sitedirected mutagenesis of the peripheral benzodiazepine receptor: identification of amino acids implicated in the binding site of Ro5-4864. Mol. Pharmacol. 46, 1160-1167 (1994).

39 Lin D, Chang YJ, Strauss JF, Miller WL. The human peripheral benzodiazepine receptor gene: cloning and characterization of alternative splicing in normal tissues and in a patient with congenital lipoid adrenal hyperplasia. Genomics 18, 643-650 (1993).

40 Venneti S, Lopresti BJ, Wiley CA. The peripheral benzodiazepine receptor (Translocator protein $18 \mathrm{kDa}$ ) in microglia: from pathology to imaging. Prog. Neurobiol. 80, 308-322 (2006).

41 Camsonne R, Crouzel C, Comar D, Maziere M, Prenant C, Sastre J, Moulin M, Syrota A. Synthesis of $\mathrm{N}-\left({ }^{11} \mathrm{C}\right)$ methyl, $\mathrm{N}$-(methyl-1 propyl), (chloro-2 phenyl)-1 isoquinoline carboxamide-3 (PK 11195): A new ligand for peripheral benzodiazepine receptors. J. Label. Compd. Radiopharm. 21, 985-991 (1984).

42 Junck L, Olson JM, Ciliax BJ, Koeppe RA, Watkins GL, Jewett DM, McKeever PE, Wieland DM, Kilbourn MR, Starosta-Rubinstein S, Mancini WR, Kuhl DE, Greenberg HS Young AB. PET imaging of human gliomas with ligands for the peripheral benzodiazepine binding site. Ann. Neurol. 26, 752-758 (1989).

43 Deane NG, Manning HC, Foutch AC, Washington MK, Aronow BJ, Bornhop DJ, Coffey RJ. Targeted imaging of colonic tumors in smad $3^{-/-}$mice discriminates cancer and inflammation. Mol. Cancer Res. 5, 341-349 (2007).

44 Wyatt SK, Manning HC, Bai M, Bailey SN, Gallant P, Ma G, Mclntosh L, Bornhop DJ. Molecular imaging of the translocator protein (TSPO) in a preclinical model of breast cancer. Mol. Imaging Biol.12, 349-358 (2010).

45 Tang D, Hight MR, McKinley ET, Fu A, Buck JR, Smith RA, Tantawy MN, Peterson TE, Colvin DC, Ansari MS, Nickels M, Manning HC. Quantitative preclinical imaging of TSPO expression in glioma using N,N-diethyl-2-(2-(4-(2${ }^{18} \mathrm{~F}$ fluoroethoxy)phenyl)-5,7-dimethylpyrazolo[1,5-a]pyrimidin-3-yl)-acetamide. J. Nucl. Med. 53, 287-294 (2012).

46 Buck JR, McKinley ET, Hight MR, Fu A, Tang D, Smith RA, Tantawy MN, Peterson TE, Colvin D, Ansari MS, Baldwin RM. Zhao P, Guleryuz S. Manning 
HC. Quantitative, preclinical PET of translocator protein expression in glioma using ${ }^{18} \mathrm{~F}-\mathrm{N}$-fluoroacetyl-N-(2,5-dimethoxybenzyl)-2-phenoxyaniline. J. Nucl. Med. 52, 107-114 (2011).

47 James ML, Fulton RR, Vercoullie J, Henderson DJ, Garreau L, Chalon S, Dolle F, Costa B, Guilloteau D, Kassiou M. DPA-714, a new translocator proteinspecific ligand: synthesis, radiofluorination, and pharmacologic characterization. J. Nucl. Med. 49, 814-822 (2008).

48 Tang D, McKinley ET, Hight MR, Uddin MI, Harp JM, Fu A, Nickels ML, Buck JR, Manning HC. Synthesis and Structure-Activity Relationships of 5,6,7Substituted Pyrazolopyrimidines: Discovery of a Novel TSPO PET Ligand for Cancer Imaging. J. Med. Chem. 56, 3429-3433 (2013).

49 Ethirajan M, Chen Y, Joshi P, Pandey RK. The role of porphyrin chemistry in tumor imaging and photodynamic therapy. Chem. Soc. Rev. 40, 340-362 (2011).

50 Kessel D, Dougherty TJ. Agents used in photodynamic therapy. Rev. Contemp. Pharmacother. 10, 19-24 (1999).

51 Locos OB, Corral A, Senge MO, Scanlan EM. Efficient Synthesis of Glycoporphyrins by Microwave-Mediated "Click" Reactions. Eur. J. Org. Chem. 1026-1028 (2010).

52 Reddi E, Zhou C, Biolo R, Menegaldo E, Jori G. Liposome- or LDLadministered $\mathrm{Zn}$ (II)-phthalocyanine as a photodynamic agent for tumours. I. Pharmacokinetic properties and phototherapeutic efficiency. Br. J. Cancer 61, 407-411 (1990).

53 Hudson R, Boyle RW. Strategies for selective delivery of photodynamic sensitisers to biological targets. J. Porphyrins Phthalocyanines 8, 954-975 (2004).

54 Paszko E, Ehrhardt C, Senge MO, Kelleher DP, Reynolds JV. Nanodrug applications in photodynamic therapy. Photodiagn.Photodyn. Ther. 8, 14-29 (2011).

55 Verma A, Facchina SL, Hirsch DJ, Song SY, Dillahey LF, Williams JR, Snyder $\mathrm{SH}$. Photodynamic tumor therapy: mitochondrial benzodiazepine receptors as a therapeutic target. Mol. Med. 4, 40-55 (1998).

56 Taketani S, Kohno H, Furukawa T, Tokunaga R. Involvement of peripheral-type benzodiazepine receptors in the intracellular transport of heme and porphyrins. J. Biochem. 117, 875-880 (1995).

57 Berns SB, Dahlman A, Johnson FM, Burns R, Sperling D, Guiltinan M, Siemens A, Walter R, Wright W. Hammer-Wilson M, Wile A. In vitro cellular effects of hematoporphyrin derivative. Cancer Res. 42, 2325-2329 (1982).

58 Roberts WG, Berns MW. In vitro photosensitization I. Cellular uptake and subcellular localization of mono-L-aspartyl chlorin e6, chloro-aluminum sulfonated phthalocyanine, and photofrin II. Lasers Surg. Med. 9, 90-101 (1989).

59 Perlin DS, Murant RS, Gibson SL, Hilf R. Effects of photosensitization by hematoporphyrin derivative on mitochondrial adenosine triphosphatasemediated proton transport and membrane integrity of R3230AC mammary adenocarcinoma. Cancer Res. 45, 653-658 (1985).

60 Salet C. Hematoporphyrin and hematoporphyrin-derivative photosensitization of mitochondria. Biochimie 68, 865-868 (1986).

61 Dougherty TJ, Gomer CJ, Henderson BW, Jori G, Kessel D, Korbelik M, Moan J, Peng Q. Photodynamic therapy. J. Natl. Cancer Inst. 90, 889-905 (1998). 
62 Agostinis P, Vantieghem A, Merlevede W, de Witte PA. Hypericin in cancer treatment: more light on the way. Int. J. Biochem. Cell Biol. 34, 221-41 (2002).

63 Nyman ES, Hynninen $\mathrm{PH}$. Research advances in the use of tetrapyrrolic photosensitizers for photodynamic therapy. J. Photochem. Photobiol. B:Biol. 73, 1-28 (2004).

64 Peng Q, Warloe T, Berg K, Moan J, Kongshaug M, Giercksky KE, Nesland JM. 5-Aminolevulinic acid-based photodynamic therapy: Clinical research and future challenges. Cancer 79, 2282-2308 (1997).

65 Senge MO. Brandt JC. Temoporfin (Foscan $^{\circledR}$, 5,10,15,20-Tetra $(m$ hydroxyphenyl)chlorin)-A Second-generation Photosensitizer. Photochem. Photobiol. 87, 1240-1296 (2011).

66 Sternberg ED, Dolphin D, Bruckner C. Porphyrin-based photosensitizers for use in photodynamic therapy. Tetrahedron 54, 4151-4202 (1998).

67 Rosenberg N, Rosenberg O, Weizman A, Veenman L, Gavish M. In vitro catabolic effect of protoporphyrin IX in human osteoblast-like cells: possible role of the $18 \mathrm{kDa}$ mitochondrial translocator protein. J. Bioenerg. Biomembr. 45, 333-341 (2013).

68 Mantione CR, Weissman BA, Goldman ME, Paul SM, Skolnick P. Endogenous inhibitors of $4^{\prime}-\left[{ }^{3} \mathrm{H}\right]$ chlorodiazepam (Ro 5-4864) binding to 'peripheral' sites for benzodiazepines. FEBS Lett. 176, 69-74 (1984).

69 Shoemaker H, Boles RG, Horst WD, Yamamura HI. Specific high-affinity binding sites for $\left[{ }^{3} \mathrm{H}\right] \mathrm{Ro}$ 5-4864 in rat brain and kidney. J. Pharamcol. Exp. Ther. 225, 61-69 (1983).

70 Ortel B, Chen N, Brissette J, Dotto GP, Maytin E, Hasan T. Differentiationspecific increase in ALA-induced protoporphyrin IX accumulation in primary mouse keratinocytes. Br. J. Cancer 77, 1744-1751 (1998).

71 Furre IE, Shahzidi S, Luksiene Z, Møller MT, Borgen E, Morgan J, TkaczStachowska K, Nesland JM, Peng Q. Targeting PBR by HexaminolevulinateMediated Photodynamic Therapy Induces Apoptosis through Translocation of Apoptosis-Inducing Factor in Human Leukemia Cells. Cancer Res. 65, 1105111060 (2005).

72 Dailey HA. Terminal steps of haem biosynthesis. Biochem. Soc. Trans. 30, 590-595 (2002).

73 Kinnally K, Zorov DB, Antonenko YN, Snyder SH, McEnery MW, Tedeschi H. Mitochondrial benzodiazepine receptor linked to inner membrane ion channels by nanomolar actions of ligands. Proc. Natl. Acad. Sci. USA 90, 1374-1378 (1993).

74 Kessel D, Antolovich M, Smith KM. The Role of the Peripheral Benzodiazepine Receptor in the Apoptotic Response to Photodynamic Therapy. Photochem. Photobiol. 74, 346-349 (2001).

75 Ben-Dror S, Bronshtein I, Wiehe A, Röder B, Senge MO, Ehrenberg B. On the correlation between hydrophobicity, liposome binding and cellular uptake of porphyrin sensitizers. Photochem. Photobiol. 82, 695-701 (2006).

76 Mojzisova H, Bonneau S, Brault D. Structural and Physico-chemical Determinants of the Interactions of Macrocyclic Photosensitizers with Cells. Eur. Biophys. J. 36, 943-953 (2007).

77 Helmlinger G, Sckell A, Dellian M, Forbes NS, Jain RK. Acid production in variant, glycolysis-deficient and parental tumors in vivo: support for hypothesized tumor metabolism. Clin. Cancer Res. 8, 1284-1291 (2002). 
78 Bombalska A, Graczyk A. Interactions of Protoporphyrin IX and its Derivatives with Benzodiazepine Receptor. Photodiagn. Photodyn. Ther. 6, 46-51 (2009).

79 Senge MO, Forsyth TP, Nguyen LT, Smith KM. Sterically Strained PorphyrinsInfluence of Core Protonation and Peripheral Substitution on the Conformation of Tetra-meso-, Octa- $\beta$-, and Dodeca-Substituted Porphyrin Dications. Angew. Chem. Int. Ed. Engl. 33, 2485-2487 (1995).

80 Senge MO. Exercises in molecular gymnastics - bending, stretching and twisting porphyrins. Chem. Commun. 243-256 (2006).

81 Sinclair RS, Tait D, Trusco TG. Triplet States of Protoporphyrin IX and Protoporphyrin IX Dimethyl Ester. J. Chem. Soc., Faraday Trans. 76, 417-425 (1980).

82 Senge MO, Forsyth TP, Nguyen LT, Smith KM. Sterically strained porphyrins Influence of core protonation and peripheral substitution on the conformation of tetra-meso-substituted, octa-beta-substituted, and dodecasubstituted porphyrin dications. Angew. Chem. Int. Ed. 33, 2485-2487 (1994).

83 Bombalska A, Graczyk A. Interactions of the Peripheral-type Benzodiazepine Receptor with Diamino Acid Derivatives of Protoporphyrin IX. J. Photochem. Photobiol., B:Biol. 94, 138-142 (2009).

84 Chen Y, Potter WR, Missert JR, Morgan J, Pandey RK. Comparative in Vitro and in Vivo Studies on Long-Wavelength Photosensitizers Derived from Bacteriopurpurinimide and Bacteriochlorin $p_{6}$ : Fused Imide Ring Enhances the in Vivo PDT Efficacy. Bioconjugate Chem. 18, 1460-1473 (2007).

85 Pandey SK, Gryshuk AL, Sajjad M, Zheng X, Chen Y, Abouzeid MM, Morgan J, Charamisinau I, Nabi HA, Oseroff A, Pandey RK. Multimodality Agents for Tumor Imaging (PET, Fluorescence) and Photodynamic Therapy. A Possible "See and Treat" Approach. J. Med. Chem. 48, 6286-6295 (2005).

86 Chen Y, Graham A, Potter W, Morgan J, Vaughan L, Bellnier DA, Henderson BW, Oseroff A, Dougherty TJ, Pandey RK. Bacteriopurpurinimides: Highly Stable and Potent Photosensitizers for Photodynamic Therapy. J. Med. Chem. 45, 255-258 (2002).

87 Morris RL, Varnes ME, Kenney ME, Li YS, Azizuddin K, McEnery MW, Oleinick NL. The Peripheral Benzodiazepine Receptor in Photodynamic Therapy with the Phthalocyanine Photosensitizer Pc 4. Photochem. Photobiol. 75, 652-661 (2002).

88 Massoud TF, Gambhir SS. Molecular imaging in living subjects: Seeing fundamental biological processes in a new light. Genes Dev. 17, 545-580 (2003).

89 Rudin M, Weissleder R. Molecular imaging in drug discovery and development. Nat. Rev. Drug Discov. 2, 123-131 (2003).

90 Verel I, Vissser GW, van Dongen GA. The promise of immuno-PET in radioimmunotherapy. J. Nucl. Med. 46, 164-171 (2005).

91 Koziorowski J, Henssen C, Weinreich R. A new convenient route to radioiodinated $\mathrm{N}$-succinimidyl 3 - and 4-iodobenzoate, two reagents for radioiodination of proteins. Appl. Radiat. Isot. 49, 955-959 (1998).

92 Verel I, Visser GW, Vosjan MJ, Finn R, Boellaard R, van Dongen GA. Highquality ${ }^{124}$ I-labeled monoclonal antibodies for use as PET scouting agents prior to ${ }^{131}$ I-radioimmunotherapy. Eur. J. Nucl. Med. Mol. Imaging 31, 1645-1652 (2004). 
93 Chen Y, Sajjad M, Wang Y, Batt C, Nabi HA, Pandey RK. TSPO 18 kDa (PBR) Targeted Photosensitizers for Cancer Imaging (PET) and PDT. Med. Chem. Lett. 2, 136-141 (2011).

94 Chen Y, Zheng X, Dobhal MP, Gryshuk A, Morgan J, Dougherty TJ, Oseroff A, Pandey RK. Methyl Pyropheophorbide-a Analogues: Potential Fluorescent Probes for the Peripheral-Type Benzodiazepine Receptor. Effect of Central Metal in Photosensitizing Efficacy. J. Med. Chem. 48, 3692-3695 (2005).

95 Chen YH, Li GL, Pandey RK. Synthesis of bacteriochlorins and their potential utility in photodynamic therapy (PDT). Curr. Org. Chem. 8 1105-1134 (2004).

96 Li G, Graham A, Chen Y, Dobhal MP, Morgan J, Zheng G, Kozyrev A, Oseroff A, Dougherty TJ, Pandey RK. Synthesis, Comparative Photosensitizing Efficacy, Human Serum Albumin (Site II) Binding Ability, and Intracellular Localization Characteristics of Novel Benzobacteriochlorins Derived from vicDihydroxybacteriochlorins. J. Med. Chem. 46, 5349-5359 (2003).

97 Graham A, Li G, Chen Y, Morgan J, Oseroff A, Dougherty TJ, Pandey RK. Structure-Activity Relationship of New Octaethylporphyrin-based Benzochlorins as Photosensitizers for Photodynamic Therapy. Photochem. Photobiol. 77, 561-566 (2003).

98 Wendler G, Lindemann P, Lacapere JJ, Papdopoulos V. Protoporphyrin IX binding and Transport by Recombinant Mouse PBR. Biochem. Biophys. Res. Commun. 311, 847-852 (2003).

99 Kessel D. Interactions between porphyrins and mitochondrial benzodiazepine receptors. Cancer Lett. 39, 193-198 (1988).

100 Verma A, Snyder SH. Characterization of porphyrin interactions with peripheral type benzodiazepine receptors. Mol. Pharmacol. 34, 800-805 (1988).

101 Hirsch JD, Beyer CF, Malkowitz L, Loullis CC, Blume AJ. Characterization of ligand binding to mitochondrial benzodiazepine receptors. Mol. Pharmacol. 35, 164-172 (1989).

102 Verma A, Facchina SL, Hirsch DJ, Song SY, Dillahey, Williams JR, Snyder SH. Photodynamic tumor Therapy: Mitochondrial Benzodiazepine Receptors as a Therapeutic Target. Mol. Med. 4, 40-45 (1998).

103 Joseph-Liazun E, Farges R, Delmas P, Ferrara P, Loison G. The $\mathrm{M}_{\mathrm{r}}$ 18,000 Subunit of the Peripheral-type Benzodiazepine Receptor Exhibits both Benzodiazepine and Isoquinoline Carboxamide Binding Sites in the absence of the Voltage-dependent Anion Channel or the Adenine Nucleotide Carrier. J. Biol. Chem. 272, 28102-28106 (1997).

104 Li H, Papadopoulos V. Peripheral-type Benzodiazepine Receptor Function in Cholesterol Transport. Identification of a Putative Cholesterol Recognition/interaction amino acid Sequence and Consensus Pattern. Endocrinology 139, 4991-4997 (1998).

105 Yeliseev AA, Kaplan S. A sensory transducer homologous to the mammalian peripheral-type benzodiazepine receptor regulates photosynthetic membrane complex formation in Rhodobacter sphaeroides 2.4.1. J. Biol. Chem. 270, 21167-21175 (1995).

106 Yeliseev AA, Kaplan S. TspO of Rhodobacter sphaeroides: A Structural and Functional Model for the Mammalian Peripheral Benzodiazepine Receptor. J. Biol. Chem. 275, 5657-5667 (2000).

107 Goldman BS, Beck DL, Monika EM, Kranz RG. Transmembrane Heme Delivery Systems. Proc. Natl. Acad. Sci. USA 95, 5003-5008 (1998). 
108 Joseph-Liauzun E, Delmas P, Shire D, Ferrara P. Topological Analysis of the Peripheral Benzodiazepine Receptor in Yeast Mitochondrial Membranes Supports a Five-transmembrane Structure. J. Biol.Chem. 273, 2146-2152 (1998).

109 Yeliseev AA, Krueger KE, Kaplan S. A Mammalian Mitochondrial Drug Receptor Functions as a bacterial "oxygen" sensor. Proc. Natl. Acad. Sci. USA 94, 5101-5106 (1997).

$110 \mathrm{Li} \mathrm{F}$, Meiler J, Ferguson-Miller S. Characterization and Modeling of the Oligomeric State and Ligand Binding Behavior of Purified Translocator Protein 18 kDa from Rhodobacter sphaeroides. Biochemistry 52, 5884-5899 (2013).

111 Baker ME, Fanestil DD. Mammalian peripheral-type benzodiazepine receptor is homologous to CrtK protein of Rhodobacter capsulatus, a photosynthetic bacterium. Cell 65, 721-722 (1991).

112 Yeliseev AA, Kaplan S. A novel mechanism for the regulation of photosynthesis gene expression by the TspO outer membrane protein of Rhodobacter sphaeroides 2.4.1. J. Biol. Chem. 274, 21234-21243 (1999).

113 Guillaumot D, Guillon S, De'planque T, Vanhe C, Gumy C, Masquelier D, Morsomme $\mathrm{P}$, Batoko $\mathrm{H}$. The Arabidopsis TSPO-related protein is a stress and abscisic acidregulated, endoplasmic reticulum-Golgi-localized membrane protein. Plant J. 60, 242-256 (2009).

114 Lindemann P, Koch A, Degenhardt B, Hause G, Grimm B, Papadopoulos V. A novel Arabidopsis thaliana protein is a functional peripheral-type benzodiazepine receptor. Plant Cell Physiol. 45, 723-733 (2004).

115 Frank W, Baar KM, Qudeimat E, Woriedh M, Alawady A, Ratnadewi D, Gremillon L, Grimm B, Reski R. A mitochondrial protein homologous to the mammalian peripheral-type benzodiazepine receptor is essential for stress adaptation in plants. Plant J. 51:1004-1018 (2007).

116 Avallone R,Cosenza F, Farina F,Baraldi C, Baraldi M. Extraction and purification from Ceratonia siliqua of compounds acting on central and peripheral benzodiazepine receptors. Fitoterapia 73, 390-396 (2002).

117 Kurumaji A, Wakai T, Toru M. Decreases in peripheral type benzodiazepine receptors in postmortem brain of chronic schizophrenics. J. Neural Transm. 104, 1361-1370 (1997).

118 Ritsner M, Modai I, Gibel A, Leschiner S, Silver H, Tsinovoya G, Weizman A, Gavish M. Decreased platelet peripheral-type benzodiazepine receptors inpersistently violent schizophrenia patients. J. Psychiatr. Res. 37, 549-556 (2003).

119 Becker DM, Kramer S. The neurological manifestations of porphyria: a review. Medicine 56, 411-423 (1977).

120 Scarf AM, Auman KM, Kassiou M. Is there any correlation between binding and functional effects at the translocator protein (TSPO) (18 kDa)? Curr. Mol. Med. 12, 387-397 (2012).

121 Scarf AM, Luus C, Da Pozzo E, Selleri S, Guarino C, Martini C, Ittner LM, Kassiou M. Evidence for Complex Binding Profiles and Species differences at the Translocator Protein (TSPO) (18 kDa). Curr. Mol. Med. 12, 488-493 (2012).

122 Gonzalez-Polo, RA, Carvalho G, Braun T, Decaudin D, Fabre C, Larochette N, Perfettini JL, Djavaheri-Mergny M, Youlyouz-Marfak I, Codogno P, Raphael M, Feuillard J, Kroemer G. PK11195 potently sensitizes to apoptosis induction independently from the peripheral benzodiazepine receptor. Oncogene 24, 7503-7513 (2005). 
123 Fujimura $\mathrm{Y}$, Ikoma Y, Yasuno F, Suhara T, Ota M, Matsumoto R, Nozaki S, Takano A, Kosaka J, Zhang MR, Nakao R, Suzuki K, Kato N, Ito H. Quantitative Analyses of ${ }^{18}$ F-FEDAA1106 Binding to Peripheral Benzodiazepine Receptors in Living Human Brain. J. Nucl. Med. 47, 43-50 (2006).

124 Zhang M, Maeda J, Ogawa M, Noguchi J, Ito T, Yoshida Y, Okauchi T, Obayashi S, Suhara T, Suzuki K. Development of a New Radioligand, N-(5Fluoro-2-phenoxyphenyl)-N-(2-[ ${ }^{18}$ F]fluoroethyl-5-methoxybenzyl)acetamide, for PET Imaging of Peripheral Benzodiazepine Receptor in Primate Brain J. Med. Chem. 47, 2228-2235 (2004).

125 Okuyama S, Chaki S, Yoshikawa R, Ogawa S, Suzuki Y, Okubo T, Nakazato A, Nagamine M, Tomisawa K. Neuropharmacological profile of peripheral benzodiazepine receptor agonists, DAA1097 and DAA1106. Life Sci. 64, 14551464 (1999).

126 Vas A, Shchukin Y, Karrenbauer VD, Cselényi Z, Kostulas K, Hillert J, Savic I, Takano A, Halldin C, Gulyás B. Functional neuroimaging in multiple sclerosis with radiolabelled glia markers: preliminary comparative PET studies with $\left[{ }^{11} \mathrm{C}\right]$ vinpocetine and $\left[{ }^{11} \mathrm{C}\right] \mathrm{PK} 11195$ in patients. J. Neurol. Sci. 264, 9-17 (2008).

127 Kita A, Kohayakawa H, Kinoshita T, Ochi Y, Nakamichi K, Kurumiya S, Furukawa K, Oka M. Anti-anxiety and antidepressant-like effects of AC-5216, a novel mitochondrial benzodiazepine receptor ligand. Br. J. Pharmacol. 142, 1059-1072 (2004).

128 Amitani M, Zhang MR, Noguchi J, Kumata K, Ito T, Takai N, Suzuki K, Hosoi R, Inoue $\mathrm{O}$. Blood flow dependence of the intratumoral distribution of peripheral benzodiazepine receptor binding in intact mouse fibrosarcoma. Nucl. Med. Biol. 33, 971-975 (2006). 


\section{Figures, Tables and Boxes}

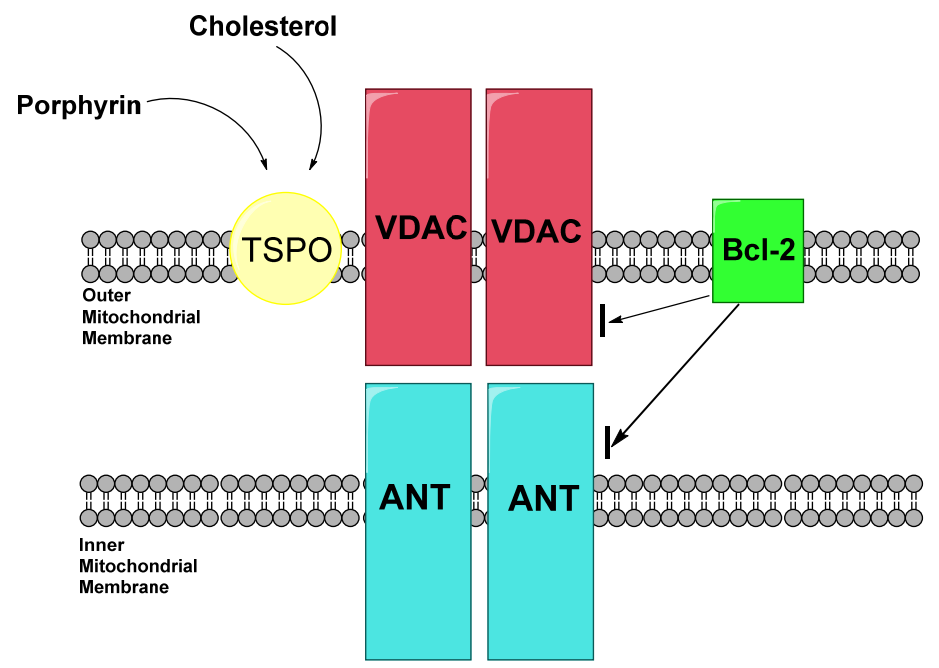

Figure 1. Schematic representation of the mitochondrial permeability transition pore and TSPO complex. The translocator protein (TSPO) is labelled yellow and the voltage-dependent anion channel (VDAC) is colored red. The B-cell lymphoma 2 protein $(\mathrm{Bcl}-2)$ is shown in green with the adenine nucleotide translocator (ANT) depicted blue.

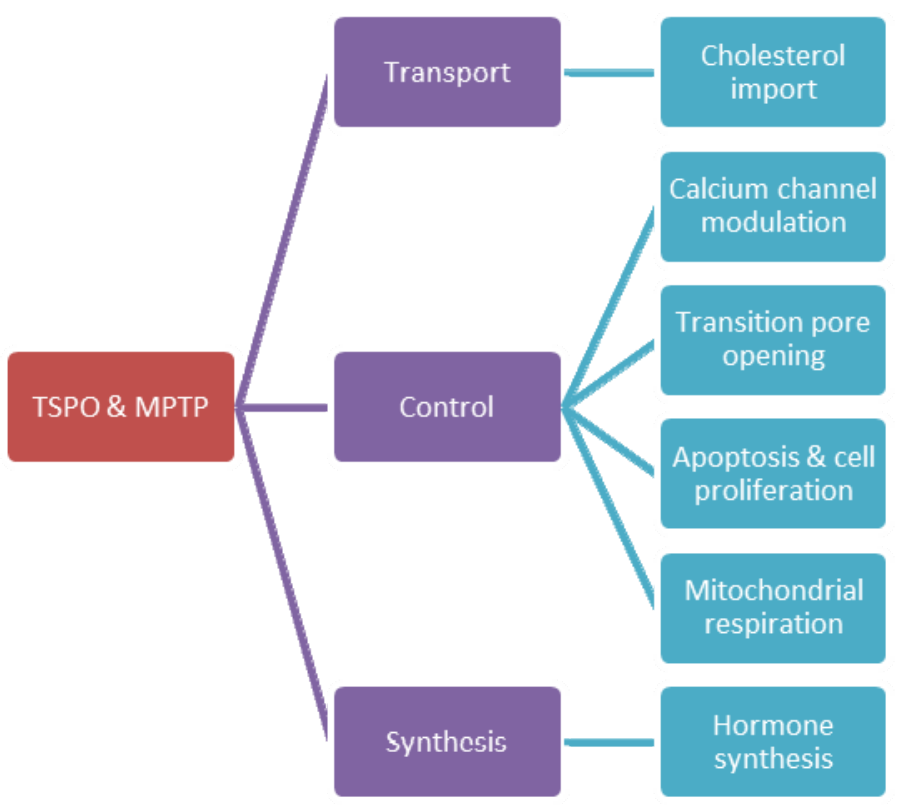

Figure 2. Flowchart of the different biological functions of the TSPO. 


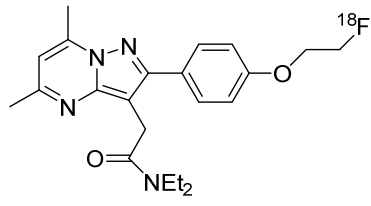

1: $\left[{ }^{18}\right.$ F $]$ DPA-714

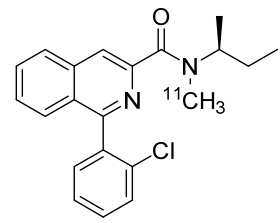

4: $\left[{ }^{11} \mathrm{C}\right] \mathrm{PK} 11195$<smiles>COc1ccc(OC)c(CN(C(C)=O)c2cc(F)ccc2Oc2ccccc2)c1</smiles>

2: $\left[{ }^{18} \mathrm{~F}\right] d_{2}$ FMDAA1106<smiles>[14CH3]N1C(=O)CN=C(c2ccc(Cl)cc2)c2cc(Cl)ccc21</smiles>

5: $\left[{ }^{11} \mathrm{C}\right] \mathrm{Ro}$ 5-4864

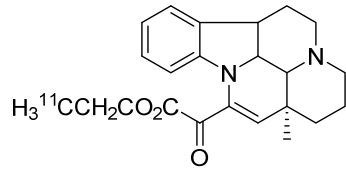

3: $\left[{ }^{11} C\right]$ vinpocetine<smiles>CCN(Cc1ccccc1)C(=O)Cn1c(=O)n(C)c2ccc(-c3ccccc3)nc21</smiles>

6: $\left[{ }^{11} \mathrm{C}\right] \mathrm{AC}-5216$

Figure 3. Classes of TSPO Radioligands. The phenoxyphenyl acetamides $[123,124,125]$, e.g., $\left[{ }^{18} \mathrm{~F}\right] d_{2} \mathrm{FMDAA} 1106$ have seen great success as radioligands for TSPO. Other classes of suitable compounds include the pyrazolopyrimidines, e.g., $\left[{ }^{18} \mathrm{~F}\right] \mathrm{DPA}-714$, vinca alkyloids [126] such as $\left[{ }^{11} \mathrm{C}\right]$ vinpocetine. Aryloxodihydropurines $[127,128]$, for example $\left[{ }^{11} \mathrm{C}\right] \mathrm{AC}-5216$ have been used extensively and successfully in animal models.
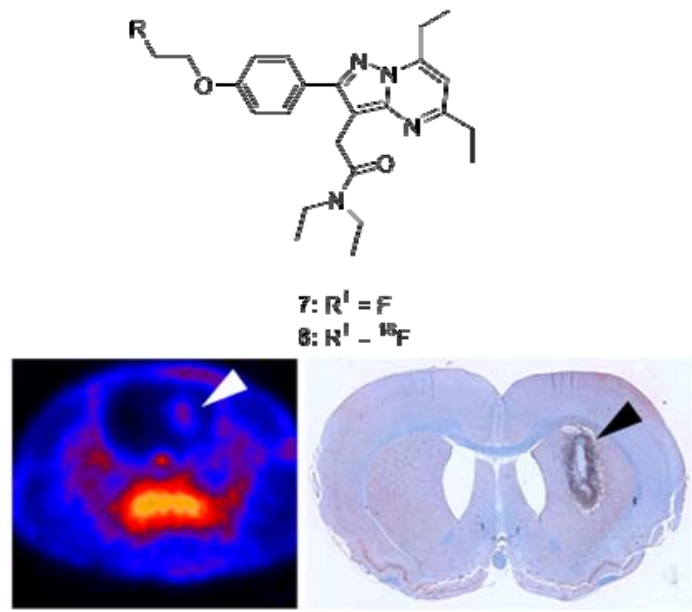

Figure 4. PET imaging of a preclinical glioma using the pyrazolopyrimidine 8. "Reprinted (adapted) with permission from [48]. Copyright (2013) American Chemical Society." 


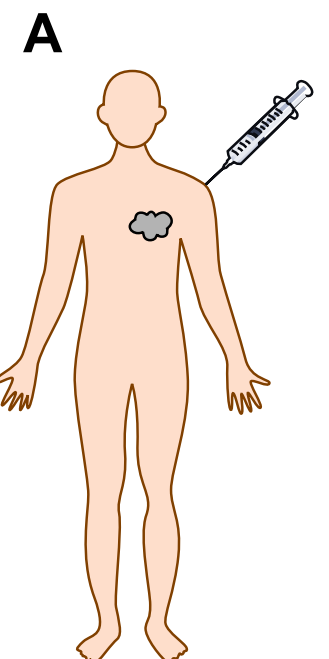

(i)

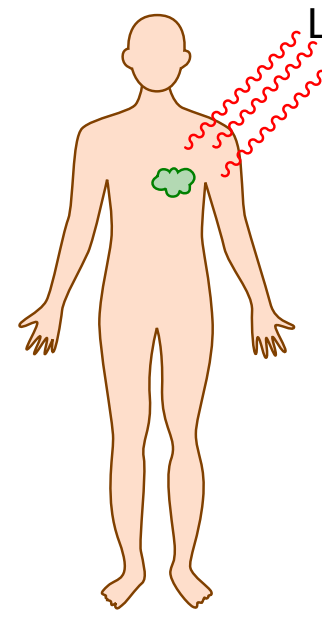

(ii)

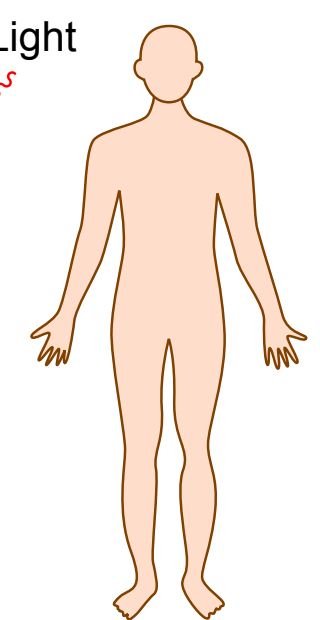

(iii)

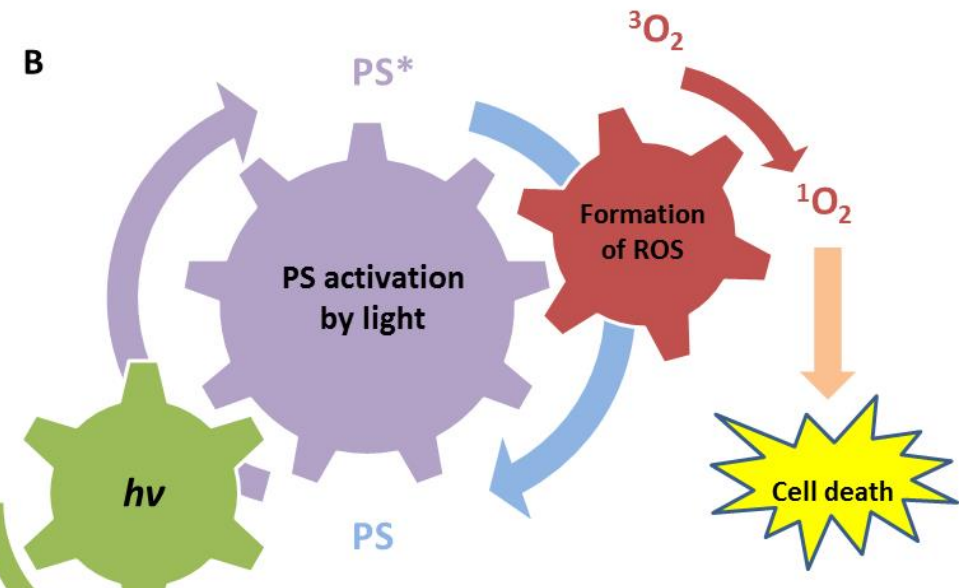

Figure 5. Graphical depiction of PDT treatment. (A) (i) PS is injected into the body. (ii) The PS is allowed accumulate at the tumor site before irradiation with light. (iii) Selective destruction of tumor. (B) Chemically this method is based on the formation of singlet oxygen and other ROS.
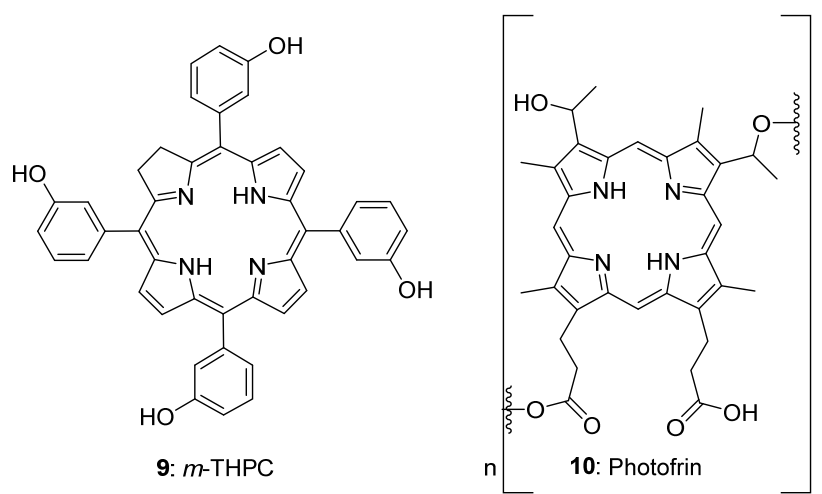

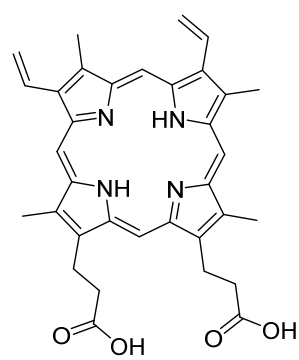

11: Protoporphyrin IX

Figure 6. Porphyrins used in PDT. 


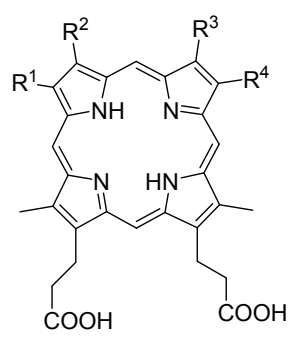

11: $R^{1}=$ methyl, $R^{2}=$ vinyl, $R^{3}=$ methyl, $R^{4}=$ vinyl = PP-IX 12: $R^{1}=$ methyl, $R^{2}=$ vinyl, $R^{3}=$ vinyl, $R^{4}=$ methyl $=P P-I I I$ 13: $R^{1}=$ vinyl, $R^{2}=$ methyl, $R^{3}=$ methyl, $R^{4}=$ vinyl = PP-XIII

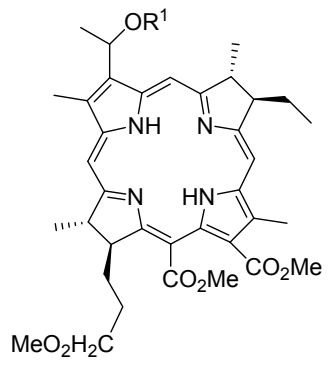

14: $\mathrm{R}^{1}=\mathrm{H}$,

15: $\mathrm{R}^{1}=\mathrm{CH}_{3}$

16: $\mathrm{R}^{1}=\left(\mathrm{CH}_{2}\right)_{2} \mathrm{CH}_{3}$

17: $\mathrm{R}^{1}=\left(\mathrm{CH}_{2}\right)_{6} \mathrm{CH}_{3}$

18: $\mathrm{R}^{1}=\left(\mathrm{CH}_{2}\right)_{10} \mathrm{CH}_{3}$

Figure 7. Protoporphyrins and rhodochlorin derivatives.
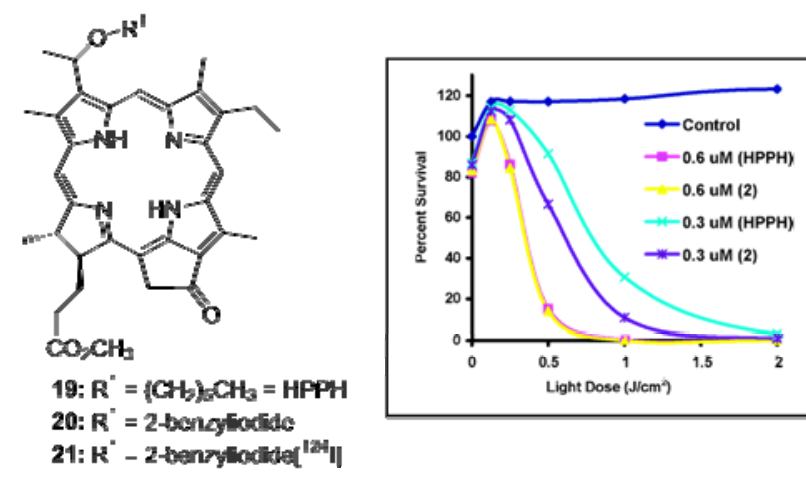

Figure 8. Pyropheophorbide derivatives and their in vitro photosensitizing activity. Variable drug concentrations and light doses of 20 and HPPH 19 in RIF tumor cells at $24 \mathrm{~h}$ post-incubation. "Reprinted (adapted) with permission from [85]. Copyright (2013) American Chemical Society."

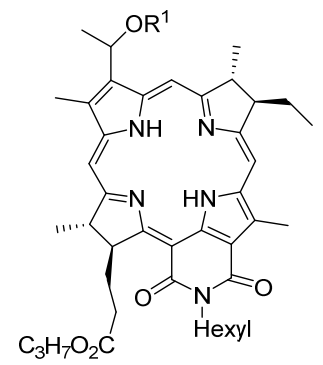

22: 7. $\mathrm{R}^{1}=\mathrm{CH}_{3}$ 23: 9. $\mathrm{R}^{1}=\left(\mathrm{CH}_{2}\right)_{6} \mathrm{CH}_{3}$ 24: 10. $\mathrm{R}^{1}=\left(\mathrm{CH}_{2}\right)_{9} \mathrm{CH}_{3}$

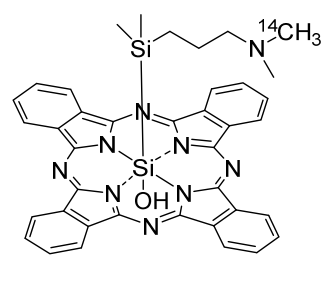

25: Pc-4

Figure 9. Stable bacteriopurpurinimide and phthalocyanine based photosensitizers. 


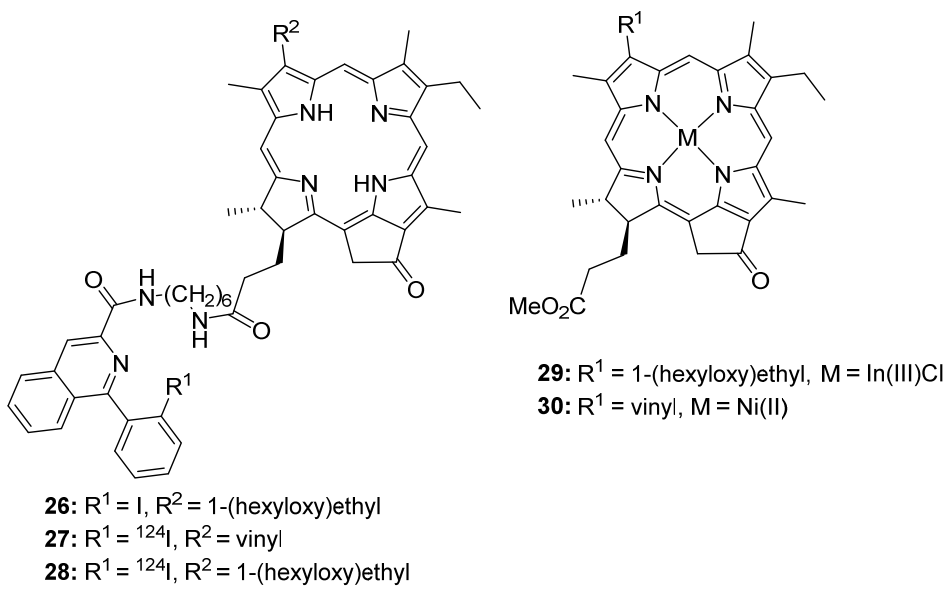

Figure 10. Library of phytochlorin derivatives.
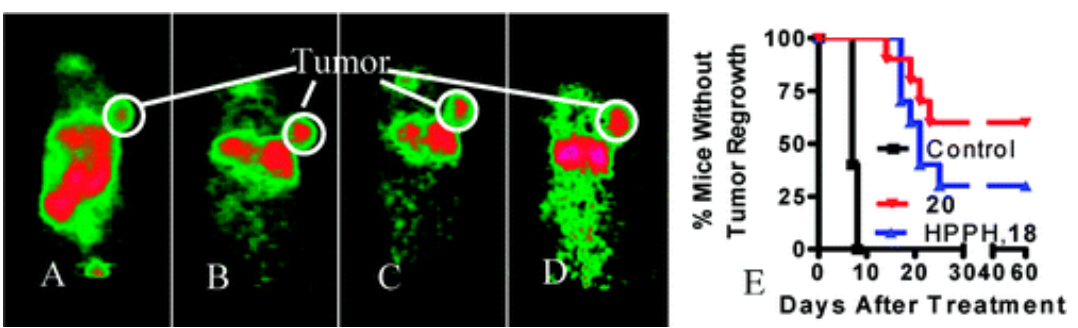

Figure 11. Conjugation of the photosensitizer HPPH to a radiolabeled derivative of PK11195. For MDA-231 tumors bearing Scid mice, 26 possesses strong tumor imaging capability. MicroPET emission imaging (coronal view) at $24 \mathrm{~h}$ (A), 48h (B),72h (C), and $96 \mathrm{~h}$ (D) post-injection of 28 (i.e., ${ }^{124} \mathrm{I}$-26)(dose: $50 \mu \mathrm{Ci}(\sim 40$ $\mathrm{ng}$ //mouse). (E) Kaplan-Meier plot for the in vivo PDT efficacy of compounds HPPH (19) and 26 at $0.4 \mu \mathrm{mol} / \mathrm{kg}$ dose. Light dose: $135 \mathrm{~J} / \mathrm{cm}^{2}, 75 \mathrm{~mW} / \mathrm{cm}^{2}$, ten mice for each group. 26 produces significantly better in vivo PDT efficacy than HPPH (19) $(P<0.0001)$. "Reprinted (adapted) with permission from [93]. Copyright (2011) American Chemical Society."

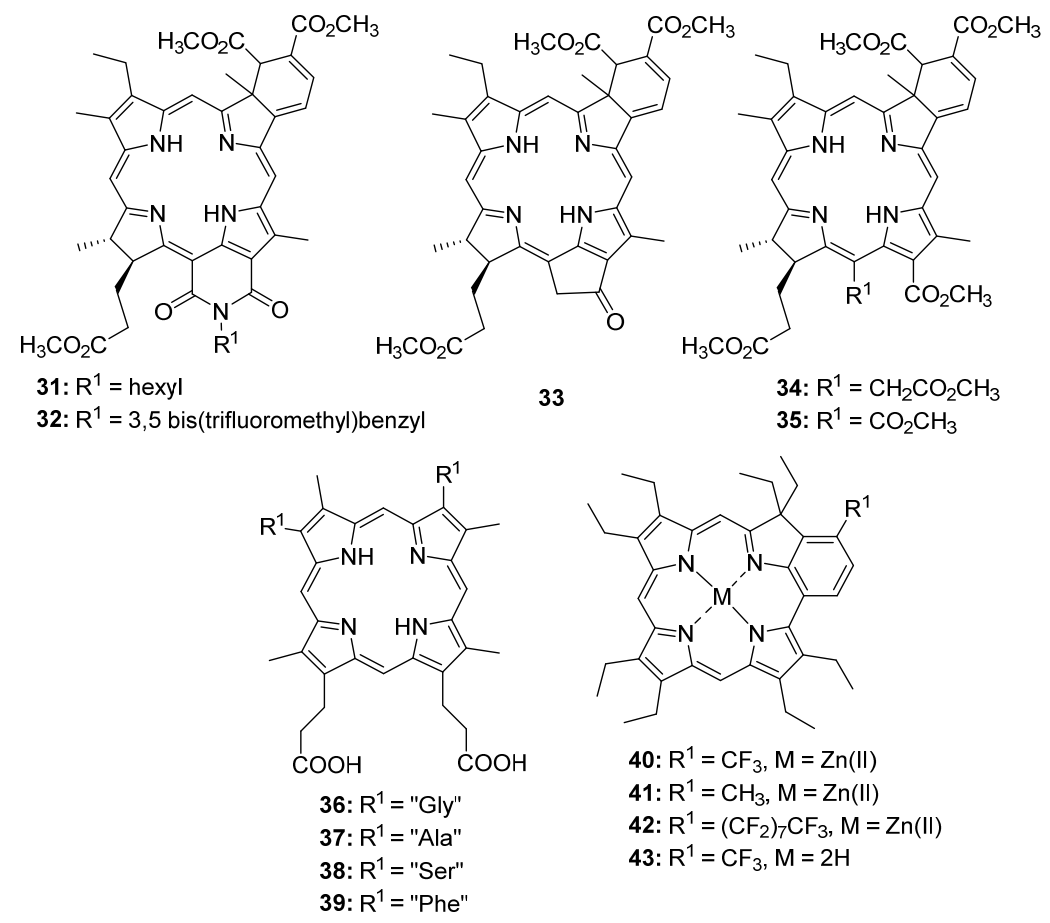


Figure 12. A range of tetrapyrrole-based photosensitizers.

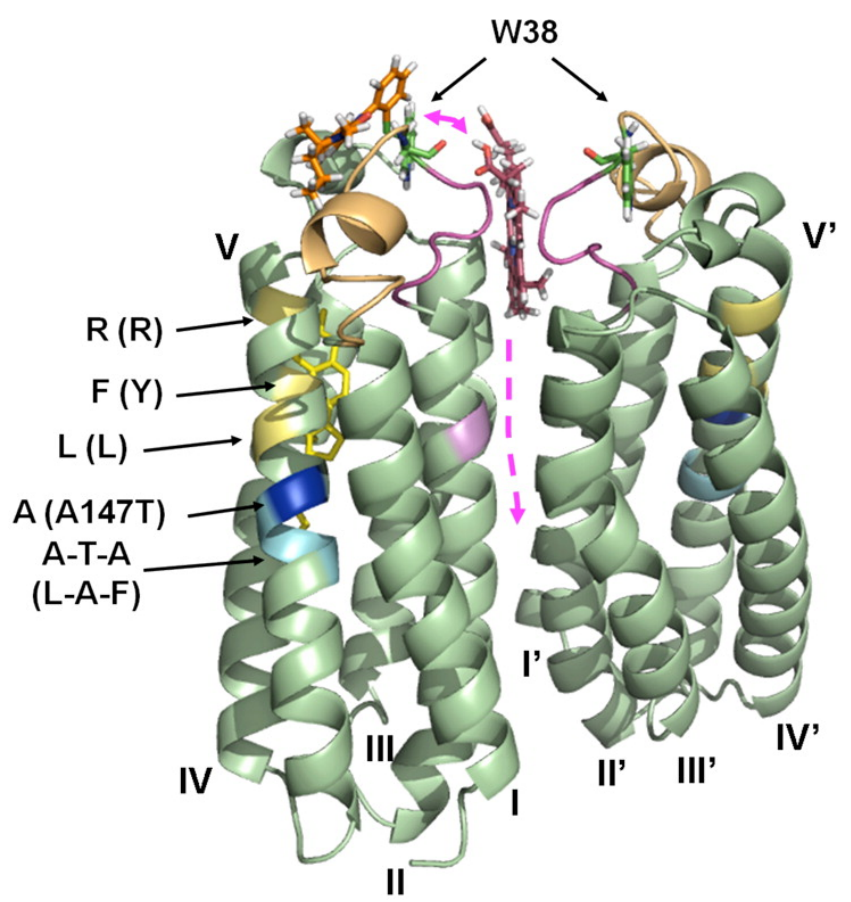

Figure 13. Model of PK11195 and PpIX binding in the proposed dimeric RsTSPO state. A suggested model of the binding sites of PP IX, PK11195, and cholesterol on RSTSPO. The ligands have been manually inserted into the model of RsTSPO on one monomer. Roman numerals have been used to illustrate the helices: W38 (green sticks), PK11195 (orange sticks), PP IX (dark purple sticks), and cholesterol (yellow sticks). Proposed PP IX binding sites on loop 1 were colored light purple and PK11195 binding site was colored light orange. The potential role of the dimer in the loading and transport of PP IX has been illustrated by a magenta dotted line indicating the potential route. "Reprinted (adapted) with permission from [111]. Copyright (2013) American Chemical Society." 